
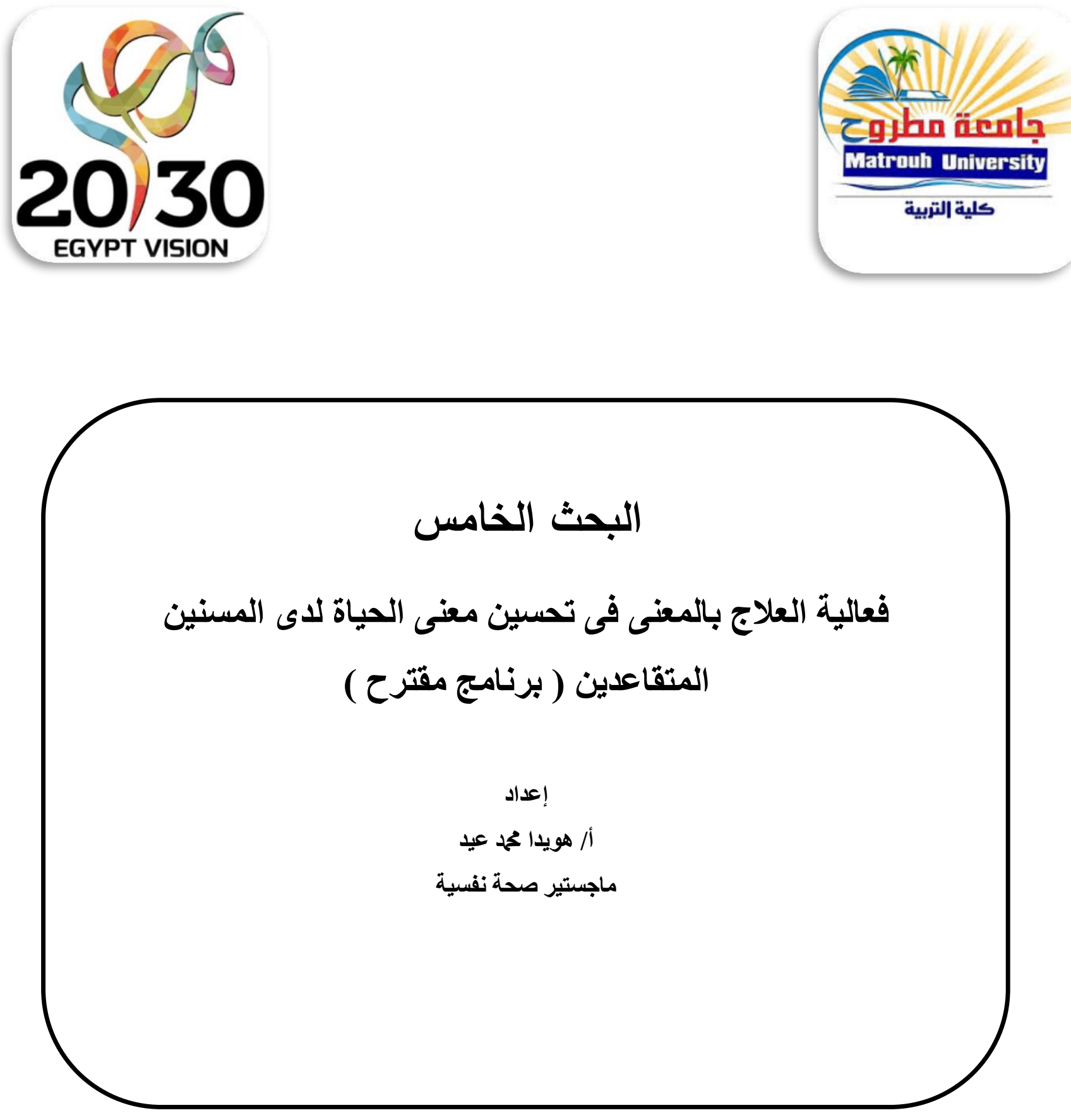


\section{فعالية العلاج بالمعنى فى تحسين معنى الحياة لاى المسنين المتقاعدين ( برنامج مقترح )}

ملخص:

إستهدف هذا المقال وضع برنامج مقترح من منظور العلاج بالمعنى فى تحسين معنى الحياة لدى

المسنين المتقاعدين ، وتتاول المقال عرض مجموعة من الدراسات السابقة عن العلاج بالمعنى ، ومعنى الحياة والتقاعد لدى المسنين ، مع تتاول مجموعة من إحتياجاتهم ومشكلاتهم حيث تنوعت

وتعددت المشكلات التى تواجـه المسنين مـا بين مشكلات إجتماعيـة ونفسية وصـية وسلوكية ،

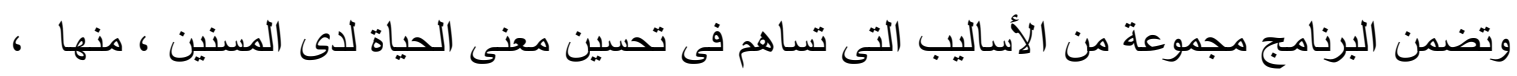
إرداة المعنى ، واسلوب التسامى بالذات ، والتفاول ، والتأمل ، وتتاول المقال الفئة التى يمكن أن يطبق عليها البرنامج المقترح وهم المسنين المتقاعدين عن العمل والذين يعانون من إفتقاد الأدوار والمكانـة الإجتماعية والذين يفتقدون معنى الحياة ، ومن الممكن أن يستغرق البرنـامج المقترح فى

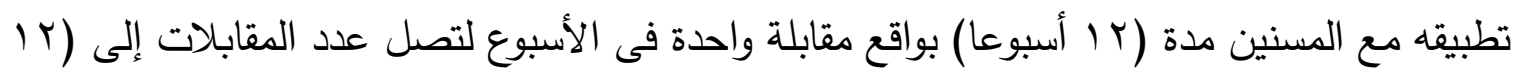
مقابلة ) تقريبا

الكلمات المفتاحية : العلاج بالمعنى - معنى الحياة - المسنين - التقاعد - مشكلات المسنين 


\begin{abstract}
The effectiveness of the Logo therapy in improving the meaning of life in retired elderly

By

Howayda Mohamed Eed

This article aimed to develop a proposed program from the perspective of semantic therapy in improving the meaning of life for the elderly retired. Social, psychological, health and behavioral problems, and the program included a set of methods that contribute to improving the meaning of life for the elderly, including the desire for meaning, the method of selftranscendence, optimism, and meditation. From the lack of roles and social status and those who lack the meaning of life, and it is possible for the proposed program to be implemented with the elderly for a period of (12 weeks) with one interview per week, bringing the number of interviews to approximately (12.
\end{abstract}

Keywords: meaning therapy - meaning of life - the elderly - retirement problems of the elderly 
تحسين معنى الحياة لاى الأشخاص هدف اسمى يسعى كل شخص في ظل الظروف المتلاحقة وسريعة التغيير إلى محاولة معايشه جودة الحياة والشعور بتحسين الحال والتوافق النفسي والاجتماعي مما يقتضي صحة نفسية إيجابية. وتعتبر دراسة معنى الحياة وجودتها من الدراسات الحديثة نسبياً في مجال الطب والصحة العامة والطب النفسي وعلم النفس والتربية، كما أن الاهتمام المتزايد بجودة الحياة، والرغبة في تقليل الآثار السلبية للمرض والإعاقة، عكست أقصى تطلعات العاملين في هذه المجالات. كما أن مفهوم معنى

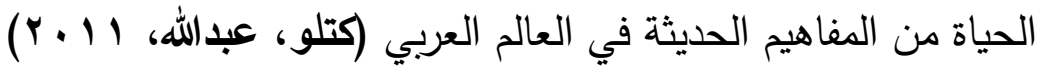
كما أن معنى الحياة وتغلب الشخص على العقبات التي تواجهه يكون صعب من دون تقديم (Frankl, خدمات مساندة ودعم إيجابي والبحث عن المعنى وتحقيقه ، حيث يؤكد فرانكل (1990:48 أن معنى الحياة هو الثئ الأساسي الذي يساعد الإنسان على البقاء حتى في أسوإ الظروف، كما يساعده على تجاوز ذاته والتوجه بإيجابية في الحياة والتوجه نحو المستقبل بتفاؤل من خلال اكتثافه للجوانب الإيجابية والقدرات والإمكانيات التي بداخله بدلاً من تركيزه على الجوانب

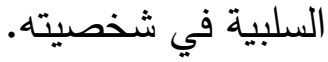
وتتطلق الدراسة الحالية من مسلمة أن العلاج بالمعنى من خلال مبادئه وأسسه النظرية وفنياته يساعد في تحسين معنى الحياة لدى المسنين المتقاعدين • والعلاج بالمعنى Logo therapy يتركز حول دافع أساسي يشكل لب حياة اي إنسان من وجهة نظر فرانكل Frankl وهو إدارة المعنى will to Meaning، الذي يدور حول معنى الحياة والوجود، ويشعر الفرد بالتوتر والاضطراب عندما يكتشف الفجوة بين الخواء الذي يعيشه والحياة التي ينبغي أن يعيشها عندما يحدد معنى لحياته ولوجوده، والذي تدور حوله كل أنشطته وسلوكياته. (منصور،

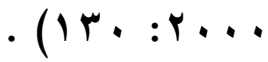


لقد أدى التقدم في مجال الطب إلى زيادة متوسط عمر الإنسان، وقد ترتب على ذللك ارتفاع عدد الأشخاص الذين يعيشون حتى مراحل متقدمة من العمر ، وطبقاً لتوقعات الأمم المتحدة فسوف ترتفع نسبة المسنين ارتفاعاً متتالياً للمجموع العام لسكان العالم، وبناء على ذلك فإنه ينبغي أن يولي الاهتمام بهذه الفئة التي تتزايد يوماً بعد يوم حتى لا يتركون عبنًا على المجتمع، فكما يحتاج المجتمع إلى سواعد الثباب وقوتهم يحتاج إلى عقل وفكر كبار السن، وبذللك يستطيع المجتمع أن ينمو

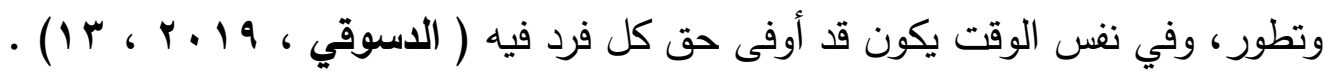
كما أن عملية التقدم الدذهل في التكنولوجيا الطبية، والتحسن الكبير في النظام الصحي والغذائي للسكان في المجتمع ، وما صاحبه من انخفاض واضح في معدلات الوفاة ، أدي إلي التحولات الطارئة على أنماط الحياة المعاصرة في شتى المجالات، فقد أدت إلى زيادة اتساع حجم شريحة المسنين وزيادة حدة مشكاتهم. كما يبدو أن التغيرات البيولوجية المرافقة للتقدم المضطرد في العمر والتراجع الملحوظ في أداء الأجهزة الحيوية لوظائفها قد أسهمت أيضاً في فقدان المسنين لكثير من مصادر قوتهم المادية والاجتماعية، وإلى تزايد شعورهم بتدني قيمة الذات لديهم، الأمر الذي أدى إلى زيادة احتمالات بروز كثير من التحديات النفسية لديهم وتزايد حاجاتهم للدعم والمساندة ( السمري، - (T) TH. 19 ولقد أظهر الجهاز المركزي للتعبئة العامة والإحصاء، أن عدد المسنين في مصر حوالي V ملايين

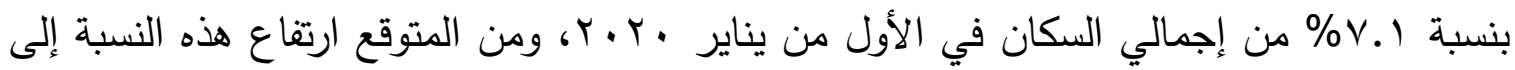

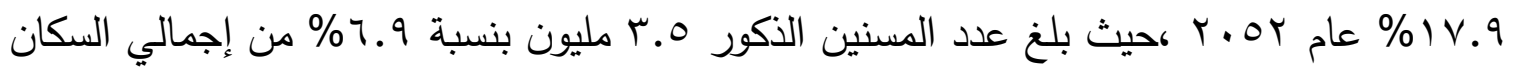
الذكور، بينما بلغ عدد المسنين الإناث ه.r مليون بنسبة r.\% من إجمالي السكان الإناث.

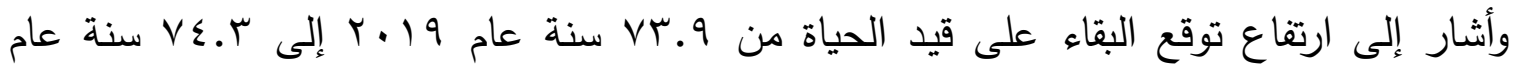

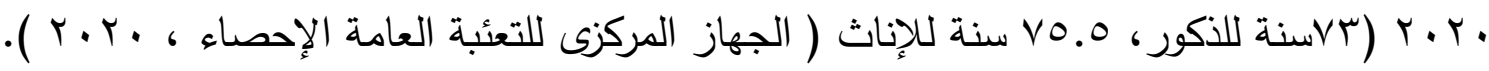
والثيخوخة مرحلة طبيعية أساسية من مراحل النمو الإنساني وهي حالة تتأثر بفسيولوجية الفرد وسيكولوجيته وبالبيئة الاجتماعية والاقتصادية والثقافية التي يعيش فيها واتجاهاتها التي يتقبلها

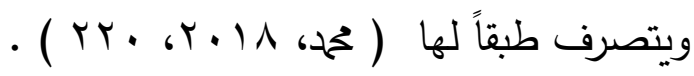


وتعد مرحلة الشيخوخة من أهم المراحل التي يمر بها الإنسان ، بسبب طبيعة وكثافة التغيرات التي تنطوي عليها، فهي تعد مرحلة بيولوجية ذات خصوصية شديدة ، بسبب سلسلة التحولات العميقة التي تتخللها، وما يلازمها من تحديات معيشية، ومشكلات اجتماعية ومصاعب نفسية ناتجة عن تقدم العمر وفقدان المكانة الاجتماعية بسبب التقاعد عن العمل ، وتراجع كثير من المكتسبات الاقتصادية والثقافية، وسوء التوافق مع متطلبات هذه المرحلة العمرية، ولما قد تتصف من بروز حالات من العزلة الاجتماعية والاكتئاب ومشاعر الوحدة والاغتراب وزيادة مظاهر الانسحاب

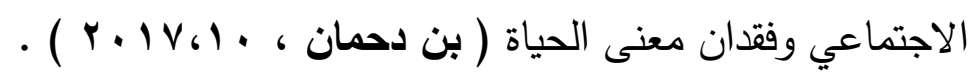
وعند التقدم فى العمر يبدأ بعض كبار السن فى تقييم ومراجعة الحياة ، حيث يقيم المسن خبراته وتجاربه فى الحياة خاصة بعد التقاعد عن الععل ، ويفكر فى السنوات المتبقية إيمانا بحتمية الموت ، وهنا يشعر البعض بالسعادة والرضا لما حققوه من إنجازات ، والبعض الأخر يشعر أن كثير من أنشطتهم لم تحقق أى عائد لهم أو للآخرين وأنها سببت بعض الآلام والمتاعب للمحيطين بهر ولأنفسهم ، وهولاء يشعرون بضعف معنى الحياة ، لذا يعد هذا التقييم أو قدرة الفرد على إستدعاء الخبرات القديمة وتصورها وإعادة تنظيمها عامل يساعد على التوصل الى تحسين معنى الحياة

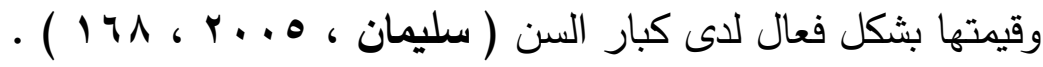
ويُعد إيجاد معنى للحياة مقدمة ضرورية لمعالجة وتخفيف المشكلات والضغوط التى قد تلم بالفرد ، فقد ثبت أن مفهوم معنى الحياة لدى الأفراد يؤثر فى كثير من مكونات الشخصية ، فإنعدام المعنى يسبب الكثير من الإضطرابات ويفقد الفرد القدرة على الإعتقاد فى الأهمية والفائدة أو الإستثارة لأداء أى فعل ، فقد تأكد أن لمعنى الحياة علاقة بالتحكم الذاتى ، كما ثبت أن من لديهخ تحسن فى معنى الحياة يكون لديهم درجات أعلى فى التماسلك والانتاج وأكثر فاعلية وإسترخاء وإستمتاع بالحياة (

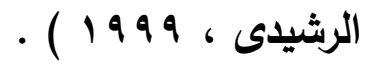
وغالباً ما تتزايد أزمة معنى الحياة مع أزمة الثيخوخة وأزمة التقاعد عن العمل ليصبح معنى الحياة

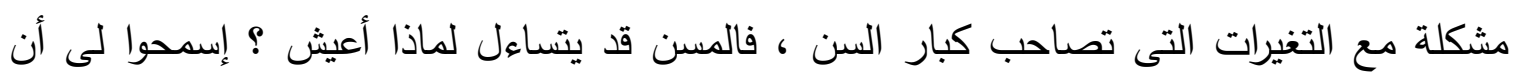
أموت ؟ لا معنى للحياة لى ؟ لتصبح حياة المسن بدون معنى ويظهر لديه خواء المعنى Lessness 
معنى الحياة أكثر من غيرهم وتحسين المصادر الثخصية والمجتمية التى تؤثر على تشكيل وتكوين

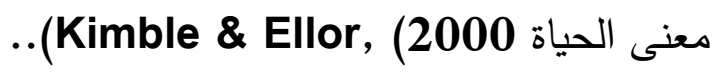

لذلك يجب على الممارسين لمهن المساعدة الانسانية خاصة فى العصر الحالى تفعيل أدوراهم المهنية وبرامج التدخل المهنى فى تحسين معنى الحياة للإنسان عامة وكبار السن خاصة ، فالإنسان يبدأ عند التقدم فى العمر بالتساؤل عن ما هو معنى الحياة ؟ وما هو الغرض الآن الحياة ؟ ذلك على الرغم من أن الثيخوخة لا تقلل من قوة الإنسان وطاقته وسعيه من أجل الحياه ، بل أن الثيخوخة تساعد الإنسان على إعادة صياغة المفاهيم بشكل جديد ، وإعادة ترتيب الإحتياجات والأهداف ، وهنا يؤكد ديفيد جاتمان David Guttmann أن العلاج بالمعنى يُعد من أفضل وأهم

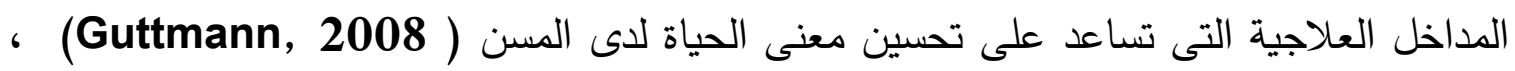
حيث يعد العلاج بالمعنى نموذجاً للتأكيد على أن كل منا يبحث عن معنى الحياة . كما أن الإفتراضات النظرية للعلاج بالمعنى تؤكد على أهمية المعنى الشخصى فى الحياة وأن تقبل الفرد لذاته وللحياة يأتى من تحقيق معنى وهدف للحياة ، وأن معنى الحياة يأتى من عدة مصادر مثل العمل والأسرة والأصدقاء والمجتمع ، ولكى يشعر الفرد بمعنى الحياة لابد من الإنجاز والتقدم فى كل هذه المجالات ، بالإضافة الى التسامى بالذات والمعاملة العادلة والتدين وتقبل الذات ، وعلى

هذا فإن ضعف معنى الحياة يؤدى بالفرد الى كثرة الإنفعالات السلبية ومواجهة الشككلات ( حسين ،

$$
\cdot(1.9 \cdot r \cdot . \cdot V
$$

وبناءاً على ما سبق قامت الباحثة بحصر مجموعة من الدراسات السابقة العربية والإجنبية والتى تتاولت متغيرات الدراسة الحالية ( العلاج بالمعنى - معنى الحياة - المسنين المتقاعدين ) وسوف يتم عرض هذه الدراسات من خلال محورين هما .

ثانياً : الاراسات السابقة :

•المحور الأول : دراسات وبحوث تناولت العلاج بالمعنى ومعنى الحياة بثكل عام ومنها: - دراسة العايش ( 1999 ) والتي إستهدفت تطبيق برنامج إرشادي بالعلاج بالمعني لتخفيف حدة الإضطرابات السلوكية لدي الطالبات المراهقات ، وأثارت نتائجها إلي نجاح البرنامج 
في التخفيف من حدة هذه الإضطرابات ، فضلاً عن أهمية الإرشاد النفسي للمراهقات من خلال تتمية الوعي لديهم بأهمية جودة الحياة وتتمية النظرة للمستقبل . - دراسة الثعراوي ( ع 1 +r ) والتي إستهدفت التحقق من فعالية العلاج بالمعني في تحسين جودة الحياة لدي عينة من الثباب الجامعي ، واشارت نتائجها إلي وجود فروق دالة إحصائية بين متوسطات رتب درجات طلاب المجموعة التجريبية ومتوسط رتب درجات طلاب المجموعة الضابطة علي مقياس جودة الحياة لصالح طلاب المجموعة التجريبية ، وهذا يشير إلي فعالية العلاج بالمعني في تحسين جودة الحياة لاي الثباب الجامعي. - دراسة فدعوس ، أحمد ( P. P ) والتي إستهدفت التعرف علي فاعية الإرشاد والعلاج بالمعني في التخفيف من ضغوط ومشكلات الحياة النفسية لاي عينة من طلبة جامعة إربد الأهلية ، وأشارت نتائجها إلي فاعلية البرنامج الإششادي بالعلاج بالمعني في التخفيف من ضغوط الحياة النفسية ، والتغلب علي مشاعر الحزن والضيق للي المجموعة التجريبية

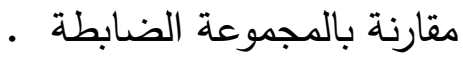

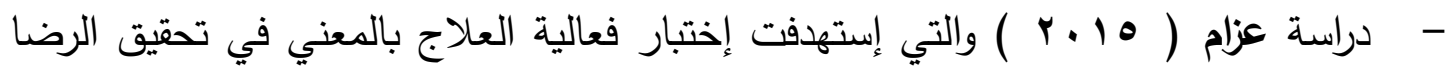
عن الحياة لدي عينة من ذوي الإعاقة الحركية ، فقد أشارت نتائجها إلي نجاح برنامج التذخل المهني بالعلاج بالمعني في رفع معدلات الرضا عن الحياة لدي المعاقين حركياً من خلال المساهمة في خفض شعورهم بالرفض والنقص والعجز ومساعدتهم علي تحقيق

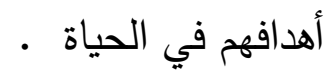

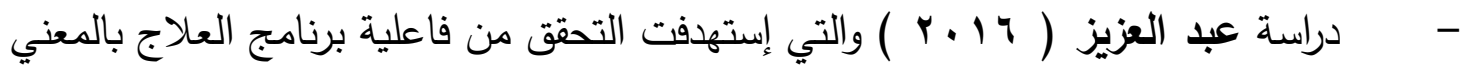
في تحسين الهذف من الحياة لدي عينة من المراهقين الصم ، واشارت نتائجها إلي وجود فروق ذات دلالة إحصائية بين متوسطات رتب المجموعة التجريبية من الذكور والإناث في القياسين القبلي والبعدي علي مقياس الهدف من الحياة لصالح القياس البعدي ، مما يشير إلي فاعلية برنامج العلاج بالمعني في مساعدة عينة الدراسة علي تحسين الهدف من الحياة - دراسة بن موسي ، بن أحمد ( 9 - 19 ) والتي استهدفت التحقق من فاعلية برنامج إرشادي قائم علي العلاج بالمعني في تحسين مستوي الطموح لدي طلاب المرحلة الثانوية 
بمنطقة جازان ، وأثارت نتائجها إلي وجود فروق ذات دلالة إحصائية بين القياسين القبلي والبعدي لأفراد المجموعة التجريبية علي مقياس مستوي الطموح لصالح القياس البعدي مما يشير إلي نجاح البرنامج الإرشادي بالعلاج بالمعني في تحسين مستوي الطموح لدي أفراد عينة الدراسة.

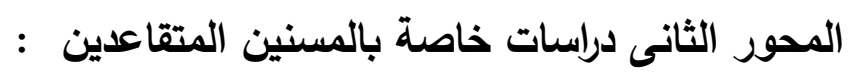

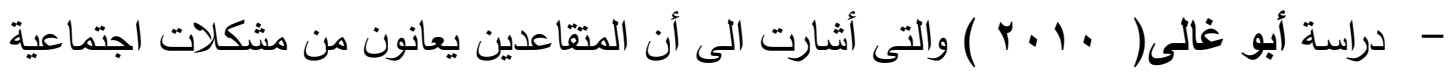
واقتصاديه بينما توجد فروق دالة إحصائيا في مستوي الصلابة النفسية لصالح الذكور.

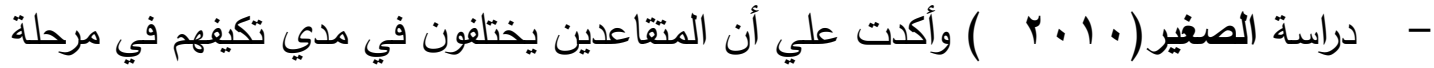
التقاعد ومدي معاناتهم لمشكلة الفراغ وفي القدرة علي تعويض الأدوار وفي معاناتهر للمشكلات المالية باختلاف خصائصهم الاجتماعية والاقتصادية وبينت نتائج الدراسة أن س؟ \%من أفراد عينة البحث يعانون من مشكلات الصحية والنفسية وتحتل المشكلات المالية المرتبة الثانية وتأتي الشكلات الاجتماعية المرتبة الثالثة ، وبينت النتائج أن ـ \% \% منهر لا يمارسون أي عمل بعد تقاعدهم - دراسة حسن (11 + P ) والتى أسفرت نتائجها على أنه قد يكون للمتقاعدين فائدة بالنسبة للأسرة نفسها من خلال مساعدة المتقاعد لأسرته بصفته أبا أو زوجا أو أخا وكذلك المرأة لصفتها إما او زوجه وأختا في كثير من المجالات التي لا يجد المتقاعد فيما سبق وقتا لعملها.

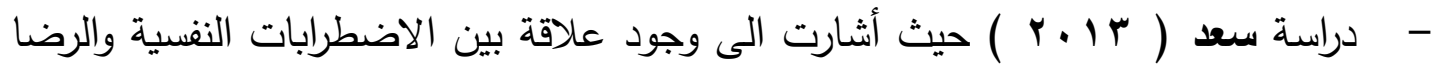
عن الحياة لكبار السن مما ينتج عنه من مشكلات مما يجعلهم دائما في توتر وقلق مستمرين وان تقبل الموت أو رفضه يعتمد علي طبيعة الفرد ومدي رضاه عن انجازاته

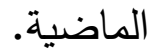

- - دراسة العتابي( 10 ـ r ) حيث أكدت أن احد المشكلات التي تواجه كبار السن هي صعوبة الإبقاء علي علاقاتهم وارتباطاتهم بيئتهم الاجتماعية وموقف المحيطين بالمسنين واتجاهاتهم نحوهم من ناحية واتجاهات المسنين أنفهر نحو تقدمه في العمر من ناحية أخري وان 
الاتجاهات السلبية نحو المسنين يؤثر علي توافقهم النفسي والاجتماعي كما يصبحوا اقل قدرة علي التحكم في حياتهم واقل توافقا نفسيا واجتماعيا . - دراسة ايمانشي وآخرون Imanishi, et al, (2015) التي إستهدفت التعرف على جودة الحياة لدى المسنين الذين يخططون لاستخدام خدمات الرعاية الداخلية الأسرية المتاحة لأولئك الذين يعانون من مرض شديد لتحديد الطريقة الأكثر فعالية لتحسين جودة الحياة من خلال هذه الخدمات، وأظهرت نتائج الدراسة أن المسن هو الذي يقرر ما إذا كان يرغب استخدام خدمات الرعاية المنزلية أو قرار البقاء في المستشفى، ويتعلق ذلك بعدة عوامل كما ذكرتها الدراسة منها تاريخ العلاج، والمستوى التعليمي، والتركيب الأسري، والذي يمثل هيكل الأسرة العائلات ذات ثلاث أجيال أو جيلين، والأزواج الذين يعيشون وحدهم، وبشكل عام أظهرت النتائج طلباً واضحاً للدعم بين كبار السن يصاحب خروجهم من المستشفى لكي يخف القلق لديهم وذلك عن طريق الدعم الأسري. - ودراسة ستنالي(Stanila, 2015 والتى إستهدفت جودة حياة المسنين في رومانيا والتي أظهرت نتائجها أنه للوصول إلى جودة حياة المسنين يجب الاهتمام بالاندماج الاجتماعي من خلال تسهيل الوصول إلى السلع والخدمات، والمرافق الترفيهية، والسكن الجيد، كما أن توفير الموارد المالية هو هدف لمفهوم الإدماج الاجتماعي لكبار السن، بالنظر إلى أن المشكلة الرئيسية التي تواجه المسنين المتقاعدين هي تلك المتعلقة بتدهور الصحة والدخل غير الكافي لضمان الحياة اليومية حيث أن ذلك يؤثر على جميع جوانب الحياة اليومية.

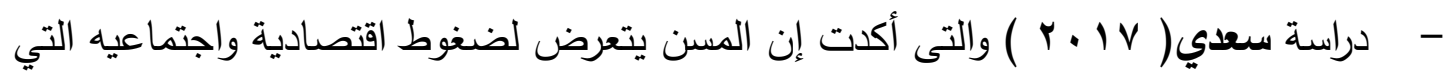
تتمثل في فقدان العلاقات الاجتماعية والعديد من الاهتمامات والنشاطات الزيادة كما أن التغيرات التي تطرأ علي ديناميات الروابط الأسرية وذهاب كبار السن إلي دور إيواء تعتبر احد العوامل المؤثرة في المسنين في هذه المرحلة وأيضا الضغوط الصحية وفقدان الشريك. - دراسة لوينغ ويو وتشونغ (Leung,Yu \&Chong, 2017 ) والتي بحثت العلاقة بين إدارة مرافق دور الرعاية ونوعية الحياة للمسنين في هونغ كونغ باستخدام كل من البيانات الكمية والنوعية ولقد أظهرت النتائج أن هناك 19 عاملاً داخلياً يؤثر في جودة حياة 
المسنين من أهمها المسافة والتهوية والأثاث والأرضيات غير المنزلقة ومرافق الترفيه والتي ترتبط بشكل إيجابي بنوعية حياة المسنين ، وبناءً على هذه النتائج، تم اقتراح العديد من التوصيات العملية، بما في ذلك تخصيص مساحات أكبر لغرف النوم، وتصميم التهوية، وتركيب أرضيات غير قابلة للانزلاق، والجو العائلي وترتيب المرافق الترفيهية.

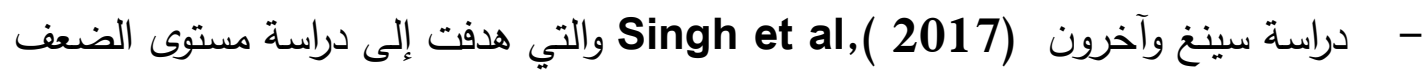
المعرفي بين كبار السن في الهند وتأثيره على جودة الحياة، وأثارت نتائجها الى أن ما يعانيه المسنين من ضعف في الادراك يؤدي إلى العديد من المشكلات الصحية الإدراكية والتي تؤثر بدورها على نوعية حياتهم وجودتها.

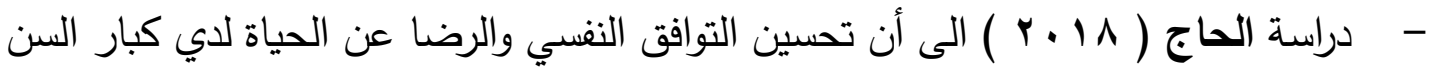
مرتبط بالجوانب الاقتصادية والاجتماعية وزيادة القدرة علي الاندماج في المجتمع والبعد عن العزلة والتعاون مع الآخرين.

- دراسة السمري ( 9 - ب ) أن التقاعد يؤثر علي تقدير الذات لكبار السن نتيجة فقدان الأدوار والمكانة الاجتماعية وفقدان السلطة والنفوذ وانخفاض الدخل لديهم ومما يلازم ذلك . فقدان شريك الحياة وما يقترن بذلك زيادة احتمالات تبنية لأنماط سلوكية غير مقبولة اجتماعيا قد لا يتقبلها الآخرين في محاولتهم لمواجهة التحديات الخارجية غير المألوفة لديهم

\section{التعقيب على الاراسات السابقة :}

أشارت الدراسات السابقة الى ما يلى :

- - أن العلاج بالمعنى له أدوار إيجابية فى تحسين معنى الحياة والرضا عنها لدى فئات متعددة من أفراد المجتمع سواء الأطفال والمراهقين والثباب والمسنين وغيرهم . - أكدت على فعالية البرامج العلاجية المتتوعة باستخدام اساليب العلاج بالمعنى في التخفيف من ضغوط الحياة النفسية ، والتغلب علي مشاعر الحزن والضيق للى المسنين وغيرهم . - أثارت أيضاً الى أن فترة التقاعد فى حياة المسنين ترتبط بالعديد من الإحتياجات والمشكلات المتنوعة التى يجب المساهمة من قبل كافة المهن فى علاجها . 
- أثارت الى وجود علاقة وثيقة بين التقاعد عن العمل ووجود مشاعر سلبية يواجهها المسن نتيجة فقدان الأدوار والمكانة الإجتماعية والسلطة والنفوذ . - - أكدت بعض الدراسات أن المشكلة الرئيسية التي تواجه المسنين المتقاعدين هي تلك المتعلقة بتدهور الصحة والدخل غير الكافي لضمان الحياة اليومية حيث أن ذلك يؤثر على جميع جوانب الحياة اليومية لهم • - أشارت الى أنه قد يكون للمتقاعدين فائدة بالنسبة للأسرة نفسها من خلال مساعدة المتقاعد لأسرته بصفته أبا أو زوجا أو أخا وكذلك المرأة لصفتها إما او زوجه وأختا في كثير من

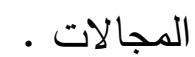
ثالثاً : المفاهيم :

\section{1- مفهوم العلاج بالمعنى :}

يُعد العلاج بالمعنى مدخلا علاجيا يستتد على مبادئ الفلسفة الوجودية والاتجاه الإنسانى فى علم النفس وقد أسسه فرانكل فى منتصف القرن العشرين تقريبا ، وهو يعنى العلاج من خلال المعنى ، حيث تم اشتقاقه من الكلمة اليونانية Logos التى تعنى Meaning ، أى أنه يركز على الوجود

الانسانى ومعنى ذلك الوجود (Lukas,2002,333 ).

ويعرف العلاج بالمعنى بأنه فهم الوجود الانسانى فى بعده الروحى ، وتعميق الوعى به وتأصيل

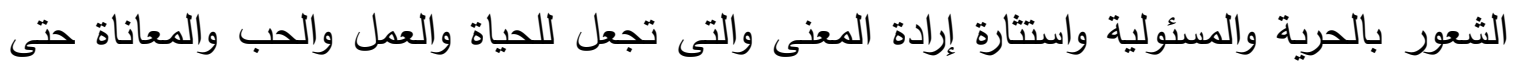
الموت معنى أصيلا يساعد الفرد على تجاوز ذاته ، والتحرك فى الحياة بإيجابية ، والتوجه نحو المستقبل بنظرة متفائلة مستقيدا من الإمكانات المحققة فى الماضى لتثكيل الحاضر ورسم صورة واضحة للمستقبل من خلال تبصيره بالجوانب الإيجابية والطاقات والإمكانات التى يمتلكها بدلا من التركيز على الجوانب السلبية وذلك فى ضوء الأسس النظرية والأساليب الفنية التى قدمها فرانكل فى نظريته عن العلاج بالمعنى ( Maria,2012) - نماك كما يعرف العلاج بالمعني علي أنه توجه علاجي إنساني يركز على الجانب الروحي في الإنسان ويهدف إلي مساعدة الفرد على إكتثاف المعاني المفقودة في حياته والتي سببت إضطرابه 
مع ذاته ، ومع عالمه الخارجي ، وذلك من خلال تبصيره بالجوانب الإيجابية والطاقات والإمكانيات

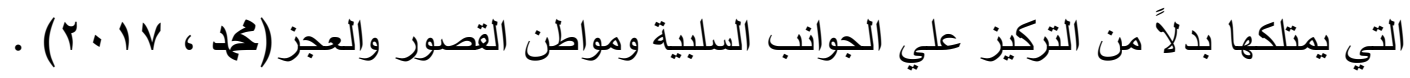
ويعرف أيضاً بأنه : إتجاه يهذف إلي مواجهة العميل بمعني حياته الفعلي وإعادة توجيهه نحوها ، فالعميل يحاول الهرب من الوعي الكامل بمهامه في الحياة وعلي المعالج أن يحسن وعى العميل بهذه المهمة الأمر الذي يساعد علي تخفيف إضطرابات العميل (عبد العال ، 9 ( ب ) . ويركز العلاج بالمعني علي هنا والأن كما يركز على علاقة الإلتقاء الشخصي الإنساني الوجودي بين المعالج والعميل أكثر من تركيزه علي التكنيكات التي تعني السيطرة على العملاء علي أن يكون المعالج صريح ، ولديه القدرة علي التعبير ويقلل من إطلاق الأحكام علي العملاء ، كما يهتم Bill O'Hanlon, ) بخبرات العميل ووجهة نظره ويربط الخبرات بالحلول ، ويشجع أفكارهم وأفعالهم $\cdot(2013$

كما يعرف أيضاً بأنه إتجاه يهدف إلي تأكيد الثعور بالحرية والمسئولية للعميل وتجعل للحياة معني يساعده علي تجاوز ذاته والتفاعل مع الحياة بمكوناتها ( الحب - العمل - المعاناه ) بإيجابية والتوجه نحو المستقبل بنظرة متفائلة ، ورسم صورة واضحة للمستقبل من خلال تبصير الفرد بالجوانب الإيجابية والإمكانيات والقدرات التي يمتلكها ( FrankI, V,2011 ) . الروافد العلمية للعلاج بالمعني : ترجع الجذور التاريخية للعلاج بالمعني لأعمال كير كجارد Kierkegaard وهيدجر Heidegger وسارتر Sorter وكتابات وجوديين أخرين مثل فرانكل Frankl حيث يركز هذا الإتجاه علي الإختيار في تثكيل حياة الثخص وأن كل شخص يتحمل مسئوليته في تشكيل حياته وحاجاته لتحديد ذاته ويؤكد علي الحاضر والمستقبل في مساعدة الثخص وأن حرية الثخص أساس لتحديد مستقبله (.Sazasz, T,2005)

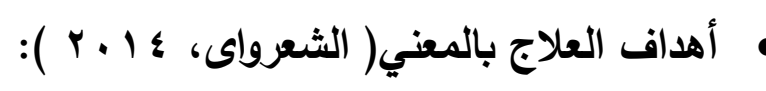

() مساعدة العميل علي أن يجد معني في حياته وتحقيق إمكانيات المعني لوجوده وإثارة إرادة الحياة لديه فيصبح لديه وعي بجوانب حياته ، ويدرك مصيره وقراراته . 
r مساعدة العميل علي تكوين إتجاهات إيجابية نحو ذاته ، فالعلاج بالمعني إتجاه تفائلي حيث يستند إلي أن الإنسان خير بطبيعته ويمتلك دافعاً أصيلاً لتتمية ذاته وترقيتها إذا توافرات له الثروط التي تساعده علي إكتثاف قدراته بنفسه ومحاولة تحقيقه للمعني. r) مساعدة العميل علي تحمل المسئولية والوعي بالذات والقدرات ، ويوضح فرانكل أن الحياة تعني الإضطلاع بالمسؤلية لكي يجد الإنسان الحلول الصحيحة لمشكلاته والقدرة علي القيام بالمهام وإتخاذ القرارات السليمة في حياته وقدرته علي التعامل مع ذاته والأخرين . §) مساعدة العميل علي تحمل المعاناة في بحثه عن المعني : فالإنسان يكون مستعداً في بحثه عن المعني كما يشير فرانكل إلي تحمل المعاناة وتقديم التضحيات حتي بحياته من أجل الحفاظ علي هذا المعني ، أما عندما تفقد الحياة معناها فيكون الفراغ الوجودي ، وهذا يشير إلي أن المعاناه أحياناً تحفظ للحياة معناها وقيمتها حيث يمكن للإنسان أن يواجه المعاناة من خلال : تحويل الألم لإنجاز، وأن يتخذ من الذنب فرصة لتغيير نفسه ، وأنه يتخذ من زوال الحياة دافعاً ليتصرف بشكل أكثر مسئولية في الحياة . مبادئ و مفاهيم العلاج بالمعنى : (أ) معنى العياة : يشير إلي أنه عندما تسأل الأفراد عن السبب الذي من أجله يعيشون حياتهر ، فإنهم سيجييون بأنهم يعيشون من أجل الأطفال الذين يجب أن تستكمل تربيتهم ، أو من أجل الصديق الذي يجب مساندته ، أو من أجل العمل الذي ينبغي إنجازه أو من أجل الحركة السياسية التي ينبغي أن تحظى بالتأييد أو من أجل العمل الفني الذي لم يزل قيد التطوير وكل هذه الإجابات يمكن إيجازها في جملة واحدة مؤداها أن هناك شخصا ما أو شيئا ما في حاجة إلى وجود أو هدف ما في حاجة إلي تحقيق ، وهنا يكمن جوهر العلاج بالمعنى الذي يعلمنا أن غاية سعينا ينبغي أن تكون من أجل معنى يدوم و يعمق مغزاه حتى في أحلك سـاعات المعاناة ، و هذا ما حدث لفرانكل الذي جاهد ليبقى و لينقل للبشرية خلاصة تجربته وسط ذللك القدر الهائل من العذاب البدني و النفسي (مسعود ، ب ا ـ م ) . 
ومن هنا تتبلور صورة معنى الحياة كما أرادها فرانكل في نظريته للمعنى ، فالحياة بالنسبة لأي فرد ذات معنى تام و غير مشروط ، يمكن تحققه بغير شرط أو قيد . و ينبغي للإنسان ألا يتوقف عن بلوغ هذا المعنى في كافة الأحوال والظروف . والمعنى الذي يقصده فرانكل ذاتي و موضوعي في آن واحد ، فهو ذاتي من حيث تتاول الإنسان له، وموضوعي من حيث أن لكل شيء معناه الحقيقي الخاص به ، و لأن المعنى لا يمنح ، و إنما يجب أن يلتمسه الإنسان و يسعى إليه ، فإن هذا الالتماس و هذا السعي لبلوغ المعنى يجب أن له له يكون في إطار من المسئولية والالتزام ، وسعيا وراء التطور والابتكارية. والمعنى هو وسائل التعبير عن الذات ، وليس هنالك معنى عالمى للحياة ولكن فقط المعانى الفردية للمواقف الفردية أى القيم التى توفر على الانسان متاعب اتخاذ القرار فالكينونة الانسانية تتجاوز ذاتها إلى معانى تكون شيئًا آخر غير ذاتها ، فالمعانى مكتشفة ويجب العثور عليها وليست مخترعة ولذلك فمهمة المعالج صقل القدرة التى تسمح لإنسان بالعثور على المعانى الفريدة وصنع القرارات المستقلة بالاضافة إلى استفادة الانسان من خبرات المواقف الفريدة التى تتكون منها الحياة ، وحسن الأختيار الذى يستند إلى المسئولية أى إلى اتخاذ القرار بتوجيه الضمير ، والرجوع إلى الضمير الحى النشط الذى يمكنه من مقاومة آثار الفراغ الوجودى والذى تبدو مظاهره فى الثعور باللامبالاة

والملل ونقص روح المبادرة وفقدان الاهتمام والثك فى المعنى ( Frankle, 2020 ) . (ب) مفهوم حرية الإرادة يقول فرانكل : ( بالرغم من كوننا في اضطرار للخضوع إلى بعض الظروف والأحوال الخارجة عن إرادتنا ، إلا أننا نكون أحرارا في اختيار ردود أفعالنا تجاه كل ذللك ) ، فالحرية كما يقول شولتر - مفهوم هام جدا في فكر و كتابات فرانكل ، الذي يؤمن بأهمية أن نكون أحرارا في مواقفنا تجاه ظروفنا و أحوالنا و وجودنا ، إذا ما كان لنا أن نتمتع بالصحة النفسية ، و لهذا فإن الثخص الذي لا يعرف كيف يستخدم هذه الحرية يعاني من العصاب الذي يسيطر عليه و يعطل إمكاناته و يؤخر نموه الإنساني و البشر ليسوا تابعين لبعض القيم و المبادئ و ليسوا آليات تستجيب بحسب ماوجهت إليه، وليسوا نتاج ما دربوا عليه في طفولتهم ، أو ما اكتسبوه من خبرات في حياتهم فحسب ، بل إنهم أحرار، وبإمكانهم أن يكونوا كذلك بدرجة كاملة ، أحرار بكل ما تحمله الكلمة من معنى , أحرار في أن يختاروا من 
السبل ما يكفل لهم ضمان الوصول إلى المعنى و تحقيق إرادة المعنى التي هي إرادة الحياة (إدي

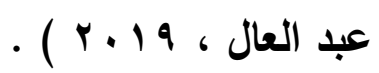

(ج)مفهوم إرادة المعنى : يعتقد فرانكل أن إرادة المعنى تمثل دافعا رئيسيا في حياة الإنسان ، بل إنها أقوى الدوافع الرئيسية , فبغيره لا يكون هناك مبرر للاستمرار في الحياة ، و هو دافع فطري و متفرد لاى كل إنسان ، و مختلف في طبيعته و توجهه من فرد لآخر ، بل و لاى نفس الفرد من موقف لآخر ، و يمكن تحقيق هذا الدافع من خلال ما نحققه في حياتتا من مهام نكتشف من خلالها ذواتتا ، وقدراتتا على التحدي لـعوقات إنجاز هذه المهام . (د) مفهوم الإحباط الوجودي : يرى فرانكل أن إرادة المعنى عند الإنسان قد تتعرض للإحباط ، وهو ما يعرف بالإحباط الوجودي و الذي قد ينتج أحيانا عن المرض النفسي ، و هذا النمط من المرض النفسي يطلق عليه فرانكل مصطلح ( العصاب معنوي المنشأ ) خلافا للعصاب النفسي المنشأ ويتولد هذا النوع من العصاب من صراعات القيم المختلفة ( أي من الصراعات المعنوية الأخلاقية ) ، ويؤكد فرانكل على أنه ليس كل صراع بالضرورة عصابيا ، فقدار من الصراع سوي و صحي ، كما أنه ليست كل معاناة ظاهرة مرضية , فالمعاناة قد تكون إنجازا إنسانيا طيبا ، خاصة إذا كانت تنشأ من الإحباط الوجودي.

(هـ)مفهوم العصاب الوجودي : إن المسئولية الهائلة التي يحمل عبئها كل إنسان تعني أنه يتحتم عليه أن يجد معنى لحياته الخاصة من خلال وجوده ، و هكذا فإن العصاب الوجودي لا يعتبر

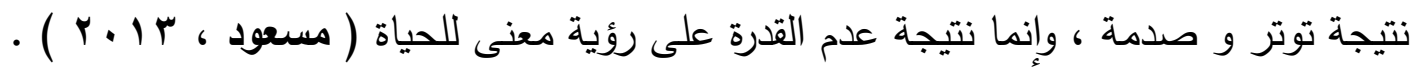
(و) مفهوم الايناميات المعنوية : يؤكد فرانكل على الديناميات المعنوية التي تدعم الصحة النفسية للفرد ، وقوامها أن يكون هناك دائما شكل من أشكال التوتر بين إنجازات الفرد و طموحاته ، أي بين ما هو عليه الآن و ما ينبغي أن يكون عليه ، وقد رأى فرانكل أن الصحة النفسية تستند إلى درجة من التوتر بين ما أنجزه الفرد و ما لا يزال عليه أن ينجزه ، بحيث يكون ناتج الديناميات المعنوية في حياة الإنسان تحديد معنى بالإمكان بلوغه . ومن هنا يكون كل ما ينبغي فعله هو إيقاظ إرادة المعنى في الإنسان من حالة كمونها ، وحث الإنسان على السعي و الجد و بلوغ الأهداف ، فهذا هو ما يميز الإنسان عن سائر المخلوقات ، 
ومنه يكون اشتقاق الوعي الذاتي و الحب و الضمير الأخلاقي ، و منه يكون الالتزام الحقيقي الذي تتوارى خلفه أقنعة الزيف و الخداع ، و تسمو به الذات فوق وجودها البيولوجي إلى رسالات و روحانيات ومعنويات يسعى إليها الإنسان بملئ إرادته الحرة ، التي حققت معنى الوجود و معنى

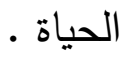

(ز)مفهوم المسئولية : و التأكيد على الالتزام بالمسئولية جزء لا يتجزأ عن العلاج بالمعنى ، و قد عبر فرانكل عن ذلك مشيرا إلى نتائج العلاج - قائلا : ( و هكذا تعيش الآن كما لو كنت تعيش بالفعل من جديد ، و كما لو كنت قد سلكت على نحو خاطئ في المرة الأولى مثلما تفعل الآن ) • و هذا هو المبدأ الذي يستثير إحساس الفرد بالالتزام و المسئولية ، فيتخيل إن الحاضر سوف يصير ماضيا ، وأن الماضي لن يتغير أو يتحسن ، في حين أن المستقبل سوف يكون من غير

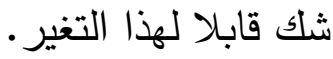
وبذلك تكون مسئولية الإنسان هي محض تعبير عن وجودهو دليل عليه ، و معناها أنه بإمكانه أن يفعل الصواب ، أو أن يرتكب الخطأ و الآثام ، و لهذا فهو إما مستحق للثواب والثناء ، وإما للوم والعقاب،ومفتاحه إلى النهوض بمسئوليته هو أن يتعلم من أخطائه و يسترشد الطريق إلى

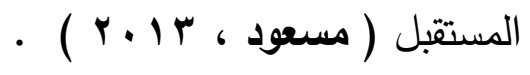

(ح) مفهوم الوعي بالذات : يحاول العلاج بالمعنى كما حدده فرانكل أن يجعل المريض واعيا كل الوعي بالتزامه بمسئولياته ، و يترك له حرية اتخاذ القرار بشأن إدراكه لنفسه كثخص مسئول

$$
\text { عن اختياره لأهدافه في الحياة . }
$$

(ط)مفهوم التسامي بالذات : يرى فرانكل أن الدافع الحقيقي في حياتتا ليس هو البحث عن ذواتتا ، وإنما البحث عن المعنى • وهذا يعني من جانب معين نسيان أنفسنا ، و تجاوزها و التسامي فوقها ، فالإنسان لا يكون إنسانا إلا إذا تجاوز ذاته و ارتقى بإنسانيته إلى ما ورائها ، و هذا ماجعل فرانكل مختلفا عن كل أصحاب النظريات الأخرى الذين اعتقدوا أن الدافع الأساسي للنمو الإنساني هو تحقيق الذات فليس الكفاح و الجهاد من أجل ما هو في الذات أو ما بداخلها ، فذلك يعد هزيمة للذات ، و إنما السعي يكون للتسامي فوق هذه الذات ـ و يشير شولتز إلى إيمان فرانكل بأننا إذا ركزنا سعينا للوصول إلى السعادة ، فلن نحقق السعادة أبدا ، فالسعادة لا 
تطلب و لا تمسك بالأيدي ، و إنما تتحقق تلقائيا بالوصول إلى المعنى والتسامي فوق الذات ، و بذلك تتحقق الذات تلقائيا و من فورها ، و تتحقق أيضا الصحة النفسية ( العايش ، 1997 ) ) (ي)مفهوم القيم : يحدد فرانكل تصنيفات ثلاث للقيم تعد السبيل الذي يمكن أن يسلكه أي إنسان لكي يصل إلى معنى حياته ، ففي رأي فرانكل أن القيم قد تكون : قيم ابتكارية تتعلق بالانجازات و أداء المهام • قيم خبراتية تقف بالفرد عند معنى ما هو خير و حقيقي،و تساعده على فهم حقيقة الحب

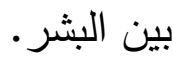
قيم اتجاهاتية توجه الفرد نحو تبني اتجاه محدد حيال آلامه و معاناته ـ و لأن الإنسان يستطيع في كل الأحوال و على كل الوجوه تحقيق هذه القيم ، فهو قادر إذن على إيجاد معنى لحياته ، كل بمفرده و كينونته الخاصة ، و ذلك من خلال خبراته و ابتكاراته ، و من خلال موقف يتخذه حيال تحديات الحياة . ومن هنا نفهم لماذا لا تخلو الحياة أبدا من المعنى ، فحتى لو كان الفرد تتقصه إمكانات الابتكار وخبرات المواجهة فإنه سيظل ذا موقف و اتجاه محدد نحو العالم و الحياة ، حتى و لو كان ذللك في إطار من الألم و المعاناة .

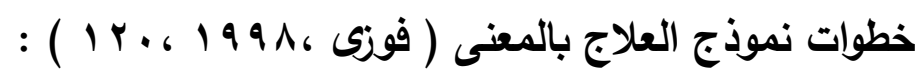
(أ) تحديد المشكلة ( التقييم الذاتى ) Distancing from symptom : تبصير العميل بمجموعة المعانى التى يفتقر إليها وسببت له المشكلة . إيجاد الهدف عن طريق المواجهة Modification of attitudes: تعويد صاحب

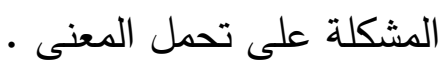

(ج) التخفيف من المشكلة Reduction of symptoms : توظيف الإرادة وتحمل المسئولية . Orientation toward meaningful activities, التوجيه نحو إدراك المعنى (د) التوف experiences and attitude

$$
\text { و اكتساب الخبرات . . }
$$


(أ) إيقاف الإمعان الفكرى : فالإقراط المبالغ فيه فكرة معينة تتضمن الحصول على السعادة كهدف من وجهة نظر الفرد قد تجعله يخطئ الهُف ولذلك يجب التفكير فى الأساليب التى تساعد على الوصول إلى الهدف ، من خلال تدعيم الاستراتيجية التالية : المقصد المتناقض ظاهريا : بمعنى توجيه الفرد نحو فكرة ايجابية تتاقض محتويات الفكرة السلبية السابقة وكلاهما يعتمد على قدرة الانسان على التسامى بالذات وعلى

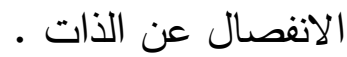

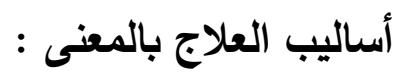

يعتمد العلاج بالمعنى على الأساليب العلاجية التالية : النصح ، التسامح ، التوجيه ، المواجهة ، الصبر ، الثجاعة ، التأمل ، الوعى بالمسئولية ، التسامى على الذات ، الفكاهة ، تحدى الموقف ، إرادة المعنى، مقابل اليأس ( بلان ، ه 1 • ، ، . . ه ) .

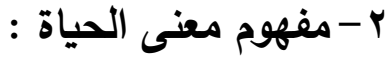

يعتبر مفهوم معنى الحياة تفسيرا لأهية حياة الفرد من جهة، وأهدافه وغاياته في الحياة من جهة أخرى، وأن معنى الحياة هو الغرض من وجود الانسان والسعي نحو تحقيق الأهداف ويتفق

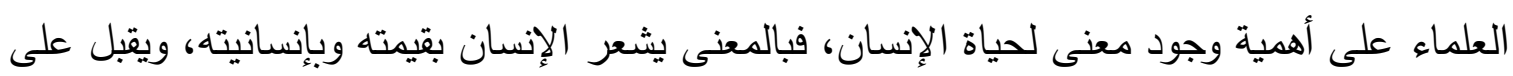
الحياة، يتفاعل معها ويتجاوب معها، ويحقق التميز والتفرد والسعي نحو تحقيق أهدافه، وبافتقاد المعنى صار الإنسان مضطربا يعاني من المشكلات والاضطرابات النفسية، ويختلف العلماء في طريقة تحقيق الإنسان للمعنى في حياته باختلاف انتماءاتهم الفكرية، ومذاهبهم الفلسفية ( الأبيض ،

$\cdot(2010$

ويُعرف معنى الحياة : بأنه تقسير أحداث الحياة التي تتعلق بشيء ما، أو حدث ما، أو خبرة ما ، أي إنه يشير إلى كل ذي دلالة وأهمية، وهو تفسير لحياة الفرد ودوافعه وأهدافه( أبو غزالة، $\cdot(r \cdot v$

أما ( الأبيض2010 ) فيعرفه بأنه : مجموع استجابات الفرد التي تعكس اتجاهاته الإيجابية أو السلبية نحو الحياة بأبعادها المختلفة، والأهداف التي يلتزم بها في حياته من دراسة، أو عمل، ومدى 
إحساسه بأهميتها وقيمتها ودافعيته للتحرك بإيجابية نحو تحقيقها، وقدرته على تحمل المسئولية، والتسامي بذاته نحو الآخرين، وتقبله لذاته ورضاه عن حياته بشكل عام. ويعرف معنى الحياة أيضاً بأنه إدراك الأمر والتماسك، إدراك الهدف من وجود الإنسان، ومتابعة

وتحقيق الأهداف ذات القيمة ومصاحبة ذلك بمشاعر الامتلاء والحيوية ( الرشيدي، 999 1) . ومعني الحياة يشتمل على ثلاثة عوامل رئيسة وهي : الاتجاه الإيجابي نحو الحياة، والعواقب

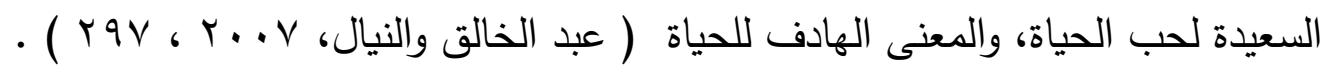
وذكرت أبو ( غزالة 2007 ) أبعاد معنى الحياة كالتالي:

- أهداف الحياة : ويقصد به إدراك الفرد للهدف من حياته، ورسالته التي يعيش من أجلها، ويضحي في سبيل تحقيقها، وإحساسه بأهميته وقيمته من خلال تحقيقه لمعنى حياته. - الدافعية في الحياة : وتعني مدى سعي الفرد في الحياة بإيجابية، وكفاحه لتحقيق أهداف ومعاني حياته، ورغبته في التمسك بالحياة والاستمرار فيها، والاستمتاع بها مما يؤدي إلى تفاؤله في الحياة. - تحمل المسئولية : ويقصد بها مدى تحمل الفرد للمسئولية تجاه نفسه، واهتمامه بالجماعة التي ينتمي إليها، والتسامي بذاته نحو الآخرين، كي يكون له دور مؤثر في الحياة الاجتماعية. - الرضا والتقبل : ويقصد بها مدى رضا الفرد عن وجوده في الحياة، وتقبله لذاته، واقتناعه بقدراته، وتفاؤله تجاه المستقبل، وتوافقه مع أسرته ومجتمعه، وشعوره بأنه فرد له قيمة تجاه الآخرين، والرضا عن علاقاته الاجتماعية بشكل عام.

\section{r- مفهوم المسنين وتصنيفاتهم :}

اختلفت الآراء وتضاربت في تعريف المسن، هل هو الذي بلغ من العمر سنا معيناً 79 عاماً مثلاُ فأكثر أو هو الذي تبدو عليه آثار تميزه بكبر السن؟ 
والثيخوخة هي مجموعة تغيرات جسمية ونفسية تحدث بعد سن الرشد وفي الحلقة الأخيرة من الحياة ومن التغيرات الجسمية العضوية الضعف العام في الصحة ونقص القوة العضلية وضعف الحواس وضعف الطاقة الجسمية والجنسية بوجه عام

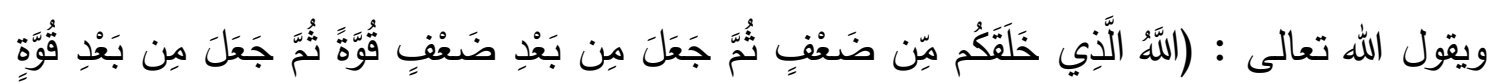

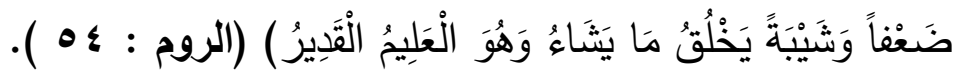
ومن المتغيرات النفسية ضعف الانتباه والذاكرة وضيق الاهتمامات والدحافظة وشدة التأثر الانفعالي والحساسية النفسية (زهران ، ه . . ب ) ) . تصنيفات كبار السن :

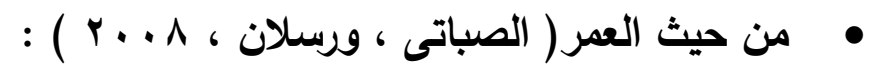

( أ ) الكهل : هو من كان في سن ( • - - • ) ولا زال يسهم في مجالات الحياة المختلفة بحيوية ونشاط ( ب ) الهرم : وهو ما كان فوق ( 10 فأكثر وازداد وهنا غالبا ما يلزم فراشه . ( ج ) المعمر : وهو من بلغ سن المائة فأكثر ولا زال أما في كهوله أو شيخوخة ممتدة . • من حيث القدرة على الحركة : فيمكن تقسيم تللك المرحلة إلى فئات ثلاثة : ( أ ) المتحرك النشط : وهو الذي لا يزال في حالة صحية تسمح له بالتحرك خارج نطاق البيت والإسهام في مختلف مجالات الحياة . ( ب) الضعيف الملازم لبيته : وهو الذي لا تساعده حالته الصحية إلا على التحرك داخل بيته لقضاء حاجته اليومية ويحتاج للمساعدة في بعض الأحيان • ( ) ) الواهن الملازم لفراشه : وهو الذي أضعفه المرض أو أقعده إلى الدرجة التي أصبح فيها واهنا هشا لا يقدر على شيء. من حيث العمل : يمكن تقسيم تلك المرحلة إلى ما يلي : ( أ ) المتقاعد : وهو الذي كان يعمل بالمؤسسات الخاصة أو الحكومة وبلغ السن التي نصت عليها التشريعات للتقاعد . - الت 
( ب ) العامل لحسابه : وهو المهني ( طبيب - محام - .. إلخ ) أو الحرفي ( سباك - كهربائي نجار - .. إلخ ) لا يتقيد بسن معينة للتقاعد وغنما يظل يعمل حتى تمنعه صحته المتدهورة من

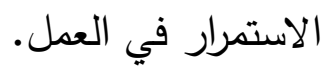
( ج ) الأجير الحر : وهو عامل اليومية الذي يعمل للى الغير ولا يرتبط مع صاحب عمل بعينه ويستمر حتى يصيبه الوهن •

( د ) صاحب الأملاكى : الذي يزاول عملا بعينه وإنما لديه أملاك يعيش على ريعها . من حيث الوضع الأسري : يمكن تقسيم تلك المرحلة إلى

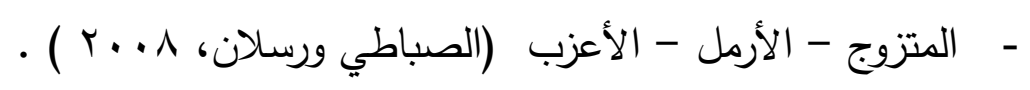

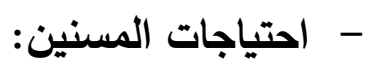

إن احتياجات المسنين تعنى افتقارهم إلى شيء ما جسميًا أو نفسيًا أو اجتماعيًا أو اقتصاديًا ويترتب عليه شعورهم بالنقص مع شعورهم بأهمية السعي لإشباع هذا الافتقار وتتحول تلك الاحتياجات إلى مشكلات في حالة عدم إشباعها بطريقة ملائمة. وإن تلك الاحتياجات تتدرج من حيث أهميتها وضرورة إشباعها ، كما تتميز بقابليتها للإثباع وسائل متعددة ، ورغم أن المسنين يشتركون في الاحتياجات العامة ألا أن لكل منهم احتياجاته الخاصة تبعًا لظروف معيشته الحالية وطبيعة الظروف التي عاش فيها قبل أن يصل إلى مرحلة كبر

$$
\text { - مشكلات المسنين: أبو المعاطي ، } 9 \text {. . . م ) . }
$$

تعريف المشكلة : هي معوق أو شيء ضار وظيفيا وبنائيا وتقف حائلا أمام إثباع الاحتياجات الإنسانية ، أو أنها ظرف يعتقد أنه مهدد لقيمة اجتماعية ، ومع ذلك يمكن تغييره عن طريق الأفعال الاجتماعية البناءة. وعرفها أبو المعاطي بأنها مجموعة التغيرات الجسمية والنفسية والاجتماعية التي تحدث للمسنين ويترتب عليها مواقف لا توافقيه فردية أو جماعية تفوق تكيفهم مع أنفسهم وبيئاتهم كما تفوق استثمارهم لإمكانياتهم وموارد المجتمع لمواجهتها دون مساعدة (أبو المعاطي ، 9 . . Y ) ) الأسباب المؤدية لمشكلات المسنين 
من أهم أسباب مشكلات المسنين ما يلي : () أسباب حيوية: مثل التدهور والضعف الجسمي و الصحي العام وخاصة تصلب الشرايين. r) أسباب نفسية: مثل الفهم الخاطئ لسيكولوجية الشيخوخة : فقد يفهم بعض الناس أن الشيخوخة معناها أن الشيخ المسن يجب أن يمشى متثاقلا يتأوه مادام قد وهن العظم منه و اشتعل الرأس شيبا وكذلك تؤثر الأحداث الأليمة و الخبرات الصادمة التي قد تهز كيان الثيخ هزا وتهذ شخصيته هداً . r) أسباب بيئية: ومنها التقاعد وما يرتبط به من نقص الدخل وزيادة الفراغ كسبب مهر هرئ للمشكلات النفسية و خاصة أن الناس يربطون بين التقاعد (عن العمل) وبين التقاعد (الجسمي النفسي) ، ويرون أن المسن عديم الفائدة ولا قيمة له وأن التقاعد معناه اعتزال الشيخ الحياة ، ومن الأسباب البيئية كذلك التغير في الأسرة و ترك الأولاد للأسرة بالزواج أو العمل خاصة في حاله حاجة الثيخ إلى رعاية صحية أو مادية ، وتفكك روابط الأسرة الكبيرة و ضعف الثعور بالواجب نحو المسنين وافتقارهم إلى الرعاية وربما الاحترام و خاصة في البيئات الصناعية ، ومنها أيضا العنوسة و العزوبة حتى سن الشيخوخة و خاصة في السيدات و الإضراب عن الزواج عند بعض

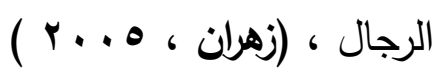
§) أسباب العولمة: شيخوخة سكان العالم والعولمة تتحوان نحو إضعاف معاملة كبار السن علي نطاق العالم، ومن أسباب ذلك : - زيادة أعداد كبار السن تشكل عبئًا اقتصادياً متعاظماً على أسرهم. - بما أن الاقتصاديات الزراعية السابقة قد أصبحت جزءاً من الاقتصاد العالمي الناشئ فإن طرق التفكير والسلوك التقليدية غالباً ما تتغير • - عندما تهاجر بعض الأسر الممتدة من الريف وتتتقل إلي المدن بحثاً عن العمل فإن مقدرتها علي دعم الأعضاء غير العاملين غالباً ما تتضاءل ( عبد الجبار ، V.... F) . أهم مشكلات الثيخوخة: فيما يلي أهم أشكال مشكلات الشيخوخة: * المشكلات الصحية: المرتبطة بالضعف الصحي العام والضعف الجسمي وضعف الحواس كالسمع والبصر وضعف القوة العضلية وانحناء الظهر و جفاف الجلد وترهله والإمساك وتصلب 
الشرايين والتعرض بدرجة أكبر من ذي قبل للإصابة بالمرض وعدم مقاومة الجسم ، (زهران ، $\cdot(r \cdot .0$

* المشكلات الاجتماعية: تعتبر المشكلات الاجتماعية من أكثر المشكلات التي تمنع تكيف المسن مع نفسه والآخرين خاصة أن للمسنين أدوارا متميزة ، فمنهم أزواج وزوجات وأخوة وأخوات وأصدقاء ومشاركين في الحياة السياسية ، أي أنهم يعيشون في وسط اجتماعي. ومن أهم أسباب حدوث المشكلات الاجتماعية للمسنين فقدان بعض الأدوار بعد تقاعدهم ، وشعورهم بفقدان أهميتهم ووجاهتهم الاجتماعية. ومن أهم مظاهر المشكلات الاجتماعية للمسنين ما يلي:

1- مشكلة فقدان المسن لبعض أدوارة الاجتماعية بعد التقاعد خاصة علاقاته مع زملاء العمل . r- مشكلة شعور المسن بالاغتراب عن المجتمع نتيجة لعدم توفر فرص مجتمعية لمشاركته في المنظمات الاجتماعية وأنشطتها التي تسهم في خدمة المجتمع الذي يعيش فيه أو الدحيطين به مما ينتج عنه عزلة المسن وشعوره بالوحدة r- مشكلة فقدان رعاية الأسرة نتيجة لما طرأ على المجتمع من تغيرات اجتماعية مرتبطة بتحول أغلب الأسر من أسر ممتدة إلى أسر نووية،مما يؤدي إلى حساسية المسن ورتابة حياته اليومية. ع- مشكلة شعور المسن بالعزلة كلما تقدم به العمر وابتعد عن الأقارب أو قصروا في رعايته بالإضافة إلى نقص مكانته الاجتماعية ه- مشكلة سوء توافق الاجتماعي بين المسن والبيئة التي يعيش فيها متمثلة في عجز وإخفاق المسن في حل مشكلاته اليومية إخفاقاً يزيد على ما ينتظره الآخرون منه أو ما ينتظره هو من نفسه (أبو

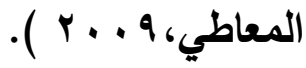
1- اضطراب العلاقات الاجتماعية:وضعف العلاقات بين كبار السن وأصدقائهم وانحصارها تدرجيا

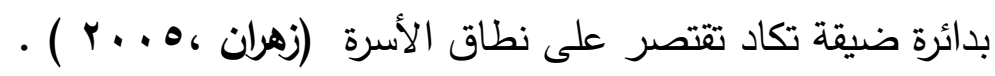
* المشكلات النفسية: تصاحب مرحلة الثيخوخة الكثير من الشكلات النفسية يتركز أهمها في الخوف من المجهول والقلق وعدم تحقيق التكيف الثخصي والاجتماعي وترتبط الشكلات النفسية 
للمسن بأنه يجد نفسه في حالة صدام مع من حوله من الأبناء والأحفاد وعدم طاعته مما يحز في نفسه ويجعله عرضه للمعاناة من التوتر والشعور بالألم النفسي. (أبو المعاطي ، 9 . . † ) ومن أهم مظاهر المشكلات النفسية للمسنين ما يلي: - المشكلات العاطفية: المتعلقة بضعف الطاقة الجنسية أو التثبث بها. فقد يتزوج الثيخ الميسور من فتاة في سن بناته ، ويتصابي ، وإذا ما ضعف جنسيًا ألقى اللوم عليها وبدأ يشك في سلوكها.وكذلك ما أحمق المرأة العجوز المتصابية. وقد يتصرف بعض الشيوخ تصرفات جنسية شاذة، وقد يأتون سلوكا لا يستحسن ولا وقر شيبهر. - ذ ذهان الشيخوخة: خبل الشيخوخة أو خرف الثيخوخة: وفيه يصبح كبير السن أقل استجابة وأكثر تمركزًا حول ذاته يميل إلى تذكر و تكرار حكاية الخبرات السابقة وتضعف ذاكرته بالنسبة للحاضر بينما تضل قوية بالنسبة لخبرات الماضي، وتقل اهتماماته وميوله. ويلاحظ نقص الطعام والأرق وتتل طاقته وحيويته ، ويصبح غير قادر على التوافق بسهوله ويشعر بقلة قيمته بالحياة وهذا يؤدي إلى اكتأب وتهيجيه وسرعة الاستثارة والعناد والنكوص إلى حالة الاعتماد على الغير وإهمال النظافة ولحسن الحظ فان نسبة حدوث ذهان الثيخوخة لا تتعدى ^.. في الألف بالنسبة للنساء 7. الألف بالنسبة للرجال. - الشعور الذاتي بعدم القيمة وعدم الجدوة بالحياة : والشعور بأن الآخرين لا يقبلونه ولا يرغبون بوجوده وما يصاحب ذلك من ضيق و توتر وقد يقدم بعضهم على الانتحار . - شعور بقرب النهاية : فقد يعيش بعض الثيوخ وكأنهم ينتظرون النهاية والقضاء المحتوم و يتحسرون على شبابهم وقد يعانون على قلق الموت - الشعور بالعزلة والوحدة النفسية: ويزيد من هذا الشعور لاى كبار السن زواج الأولاد و انشغالهم كلا في حاله و عالمه الخاص ، موت الزوج ، وقدم العمر و ضعف الجسمي و المرض أحيانا مما يقلل دائرة الاتصال الاجتماعي. وقد تقتصر العلاقات الاجتماعية على الأولاد وحفدته و أسباطه. - الأنانية: قد تشاهد عند بعض كبار السن فيلاحظ ازدياد اهتمامهم بنفسهم مثل أنانية الأطفال حيث يريد اهتمام خاص به وبطلباته قد تؤدي إلى تهديد سعادة الزوجية لأولادهم. 
- التطرف في نقد السلوك الجيل التالي: وخاصة الأولاد و الأحفاد ونقد المعايير الاجتماعية وهذا

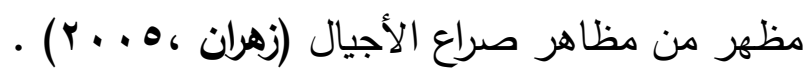
- مشكلة الاكتئاب : وذلك نتيجة لزيادة الضغوط التي تعجل بحدوث الاضطرابات الاكتئابية 口 مشكلة الملل والسأم وشعور المسن بأنه أصبح كائنا ينتظر الأجل،حيث لا أهداف ولا مطامحهمما يجعله عرضة للاضطرابات النفسية كالخمول والانطواء والسلبية المستمد من الإحساس بالعزلة على النفس وذللك بسب التراكمات السلبية بسبب من يعيشون معه وحوله من الناس. مشكلة القلق نتيجة خوف المسن من المستقبل والمبالغة في التفكير فيه ومقارنة مستقبله بمن حوله من الناس وعجزه من مجاراتهم مما يؤدي إلى تراجعه في كل ما يقوم به من أنشطة ويسبب قلقا

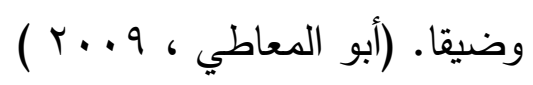

* المشكلات الاقتصادية: يؤثر كبر السن على الحالة الاقتصادية للمسن حيث يفقد عمله في أغلب الأحيان نتيجة وصوله لسن التقاعد وبالتالي يقل دخله مع زيادة احتياجاته وزيادة الأسعار في نفس الوقت ،مما يؤدي إلى وجود مشكلات اقتصادية تواجه غالبية هؤلاء المسنين.

\section{ومن أهم مظاهر المشكلات الاقتصادية ما يلي}

- مشكلة نقصان دخل المسن نتيجة فقده لعمله أو تقاعده خاصة إذا كان يعمل في أعمال حكومية،أومن يعمل في مهن حرة أو حرفية فان تقدمه في السن قد يحول دون تمكنه من ممارسة العمل بنفس القدر الذي كان يمارس به قبل كبر سنههمما يؤدي إلى نقص الدخل وانخفاض مستوى

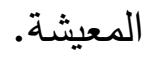
- مشكلة زيادة تكاليف حياة المسن واحتياجاته إلى مصروفات إضافية في تلك المرحلة العمرية نتيجة احتياجه إلى العلاج أو نمط معين من التغذية مما يمثل عبئًا اقتصاديا إضافياً على المسن وأسرته

- قصور التظظيمات والتشريعات التأمينية عن ضمان حياة ملائمة وكريمه للمتقاعدين في كثير من الدول نظرا لانخفاض قيمة هذه المعاشات إذا وجدت أو عدم استفادة الكثير من المسنين منها في 
أحيان كثيرة أواثبات المعاش الثهري وعدم زيادته في بعض الدول بنسبة تتمشى مع تصاعد

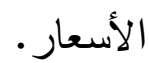

- رفض سوق العمل المعاصر والمستحدث تشغيل كبار السن بل ومحاولة إحالة العاملين إلى التقاعد إجباريا وعدم رغبة أصحاب الأعمال في تشغيل المسنينهما يقلل فرص عمل المسن وعدم قدرته على تحسين دخله ورفع مستوى معيشته. - مشكلة تتصل بعض الأبناء من مسئولياتهم تجاه رعاية آبائهم اقتصاديا،مما يمثل مشكلة بالنسبة للآباء كبار السن خاصة في حالة عدم وجود مصدر دخل ثابت لهم،أوفي حالة عدم استعدادهم لتلأك الظروف من خلال ادخار ما يكفيهم للمعيشة الكريمة (أبو المعاطي ، 9 . . r ) ) . - مشكلة سن القعود: وسن القعود هو ما يعرف عادة باسم سن اليأس وهو عند المرأة يتعين بمرحلة انقطاع الحيض (في الحلقة الخامسة من عمرها ) وعند الرجل يتعين بالضعف الجنسي الأولى أو الثانوي و تضخم البروستاتا ( في الحلقة السادسة من عمره). ويكون سن القعود مصحوبا في بعض الأحيان باضطراب نفسي أو عقلي قد يكون ملحوظا أو غير ملحوظ ويكون ذلك في ذلك في شكل الترهل والسمنة والإمساك والإجهاد و الذبول العصبية و الصداع والاكتئاب النفسي و الأرق ،ئي ، وعموما فإن أعراض سن القعود تثاهد في المدينة أكثر منها في الريف ولدي المثقفين أكثر منها

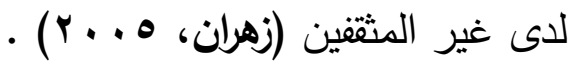
- مثكلة التقاعد: وتعتبر على رأس المشكلات التي يجب وضعها في الحسبان. فعندما يحل وقت التقاعد و ما يصاحبه من زيادة الفراغ ونقص الدخل يشعر الفرد في أعماق نفسه بالقلق على حاضره و الخوف من مستقبله مما قد يؤدي إلى الانهيار العصبي و خاصة إذا فرضت عليه حياته الجديدة بعد التقاعد الفجائي أسلوبا جديدا من السلوك لم تالفة من قبل ولا يجد في نفسه المرونة الكافية لسرعة التوافق معه خاصة إذا لم يتهيأ لهذا التغير ، وخاصة إذا شعر وأشعره الناس أنه قد أصبح لا

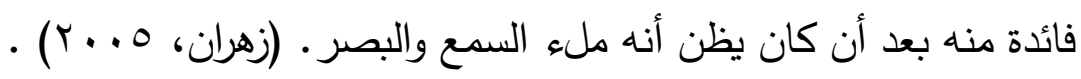

البرنامجج المقترح باستخدام العلاج بالمعنى لتحسين معنى الحياة للمسنين المتقاعدين: 1 - أهداف البرنـامج : تتحدد أهداف التدخل المهنى طبقا للهدف الرئيس للبحث وهو تطبيق نموذج العلاج بالمعنى لتحسين معنى الحياة للمسنين المتقاعدين ، وينقسم إلى عدة أهداف فرعية : 
(أ) تكوين علاقة مهنية علاجية مع المسن وفهم عالمه الذاتى للوصول إلى فهم ذاته ، وتثجيعه على التعبير عن مشاعره الايجابية أو السلبية المرتبطة بفقدان الهدف ومعنى الحياة ، أو الثـعور بالفراغ الوجودى مثل الملل والـلا مبالاة وضـفف القدرة على المبادرة ، بالاضـافة للأفكار السلبية (اللاعقلانية التى تعوق تحقيقه لأهدافه ، والتركيز على الحاضر أكثر من

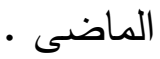

مساعدة الحدث على تحسين تفاعلاته وعلاقته بزملائه ومشرفيه والمجتمع المحيط به للتخلص من مشاعر الحزن و الضيق والإكتئاب والعزلة والوحدة . (ج)مساعدته على رؤية دوره فى خلق عالمه الجديد بعد التقاعد ، وزيادة وعيه بأنه مسئول عن مشكلته والمشـاعر المصـاحبة لها ، وحلها - مـع مراعـاة التـدرج عند مواجهته بــللك والاعتراف بحاجته لمساعدة مهنية للتخلص من إلقاء اللوم على الآخرين أو الذات حتى تولا لديه الدافعية الذاتية للتغيير وصنع قرارات جديدة مسئولة وتحمل نتائجها . (د) بـث النظرة التفاؤلية للحياة ، وتقبل الواقع الحالى الذى قد يمكنه تغييره أو تغيير أسلوب الاسـتجابة لـه بالصـبر والمرونـهـ إذا تخلـي عن بعض الثـروط المرتبطـة بمعـانى دنيويـة لاعقلانية بسبب تقاعده من جانب وإفتقاده لبعض أدواره الإجتماعية من جانب أخر ، وآثاره المترتبة علية ، وخلق معنى للحياة فى كل ما يتعرض له أو يعانيه من خلال أسلوب التأمل

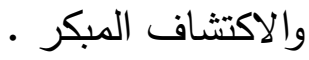

(هـ)مساعدة المسن فى التغلب على مشاعر الذنب والنقص الذي يعاني منهه ومساعدته علي إشباع إحتياجاته خاصة الإجتماعية والنفسية منها والذي ريما يفتقدها كونه إفتقد الكثير من أدواره ووظائفه.

(و ) حث المسن على التفكير فى هدف وجوده في الحياة وإبتكار أهداف جديدة والسعى لإنجازها حتى يدرك معنى حياته وتتضح أمامه معانى أخرى جديرة بالإهتمام فيسعي جاهداً من أجل تحقيقها -

(ز) مسـاعدة المسـن على التخلص مـن الضـغوط النفسية التى تقع عليـه ، وبـث روح الأمـل والتفاؤل في نفسـه ومسـاعدته علي تحقيق ذاته وبـث الثقـة في نفسـه ، ومسـاعدته علي 
إستثمار الجوانب الإيجابية في شخصيته وكذا الإمكانيات والموارد المتاحة في البيئية وكيفية الإستفادة منها بما يحقق أهدافه الحياتية . r - المستفيدين من البرنامج :

هم المسنين المتقاعدين عن العمل والذين يعـانون من إفتقاد الأدوار والمكانـة الإجتماعيـة والذين يفتقدون معنى الحياة .

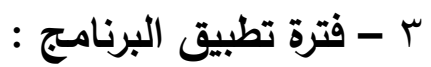
قد يستغرق البرنامج المقترح مـع المسنين مدة (r أسبوعا) بواقع مقابلة واحدة فى الأسبوع ليصل عدد المقابلات إلى (r ا مقابلة ) تقريبا ـ ع- خطوات تنفيذ البرنامج وفقا لمراحل نموذج العلاج بالمعنى: (أ) تحديد المشكلة (التقييم الذاتى): تبصير الحدث بمجموعة المعانى التى يفتقر إليها وسببت له

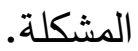

(ب) إيجاد الهدف عن طريق المواجهة: تعويد صاحب المشكلة على تحمل المعنى • (ج) التخفيف من المشكلة: توظيف الإرادة وتحمل المسئولية . (د) التوجيه نحو إدراك المعنى: اتخـاذ القرار والاشتراك فيـه وفى الأنشطة المختلفـة واكتسـاب

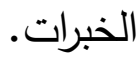

\section{0 - استراتيجيات البرنامج :}

(أ) اسـتراتيجية إيقـاف الإمعـان الفكرى : عـن طريـق توجيـه المسـن إلى عـدم التركيز فـى الموضوعات التى تعوق تحقيق أهدافه وممارسة أدواره وطرق وأساليب إتخاذ قرارته والتركيز فقط علي المهام التي يستلزم القيام بها للوصول الي الثعور بأهيميته في الحياة والتوجها نحوها بطريقة إيجابية . (ب) استراتيجية المقصد المتتاقض ظاهريـا : عن طريق تشجيع المسن على تحدى ذاته ومخاوفه وقلقه المتوقع والتغلب علي المشاعر السلبية وبث روح الأمل والتفاؤل والثقة في 
ويتضمن برنامج التذخل المهنى ما يلي :

(أ) بناء العلاقة المهنية :

ويتحقق من خلال البداية المناسبة مع العميل (المسن ) وفق نموذج التدخل المهنى ويتم ذلك من

الاهتمام بالمسن والتعرف علي جوانب شخصيته. شرح طبيعة عمل الباحثة وإمكانية العمل مع المسن للتخفيف من الاثار الناتجة عن تقاعده وإفتقادة لبعض أدواره الإجتماعية وإنخفاض مستوي ذاته . تحديد الأدوار التي سوف تمارسها الباحثة والمسن للمساهمة في تحسين معنى الحياة لدي

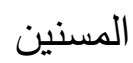

أساليب البرنامج : الاساليب العلاجية التى يعتمد عليها العلاج بالمعني وهي : نصح العميل : من خلال التوضيح له بأن الإقامة في المؤسسة هي فترة مؤقتة لحين تتمية قدراته وإستعدادته لمواجهة أعباء الحياة وإثبات الذات بالتعليم المتميز أو التدريب المهني الجيد وذلك للحصول علي فرص جيدة للخروج من المؤسسة وممارسة حياته والإندماج في

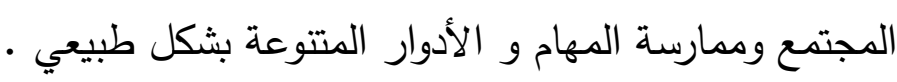
حث المسن وتوجيهه لإبتكار أهداف جديدة والسعى لإنجازها حتى يتوصل لمعنى حياته وتتضح أمامه معانى أخرى يستطيع الوصول إليها أو تحقيقها. تنمية الوعى بالمسئولية ومساعدة المسن على التخفيف من الآثار الإجتماعية والنفسية التي يعاني منها نتيجة تقاعده وإفتقاده لأدواره ومكانته الاجتماعية و شعوره بالنقص . • أسلوب التأمل : من خلال مساعد المسن على خلق معنى جديد للحياة فى كل ما تعرض له أو عاني منه من آثار سلبية نتيجة الضغوط والمشكلات التي تعرض لها في حياته سواء قبل التقاعد عن العمل أو بعده . 
• منح الأمل والتفاؤل : من خلال إقناع المسن بضرورة تبني مجموعة من الأهداف والطموحات الإيجابية وبث الشعور بالأمل في نفسه والثقة في ذاته لبذل أقصي طاقة للعمل علي تحقيق هذه الأهداف والطموحات .

إرادة المعنى : من خلال تشجيع المسن على التعبير عن حاجاته ورغباته والسمو بها على الذات وتحديد أهدافه وتوجهاته الحياتية وتوصيفها فى مسارات ايجابية مرتبطة باختياراته

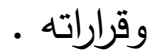

المواجهة : من خلال مساعدة المسن على مواجهة المشاعر السلبية الذي يعاني منها كالثعور بالذنب أو النقص والإحباط والاكتئاب والعزلة وبث الثقة في نفسه .

\section{مراجع البحث}

أولاً : المراجع العربية :

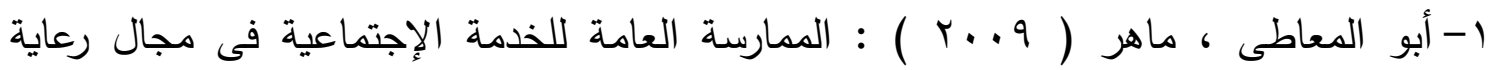
المسنين ، القاهرة ، مطبعة نور الإيمان .

r- أبو غالي ، عاطف ( • • ( ) ) : مشكلات المسنين وعلاقتها بالصلابة النفسية دراسة ميدانيه علي عينه من المسنين الفلسطنين في محافظات غزه ، غزة ، جامعة الاقصي ، قسم علم النفس ، كلية التربية ،مجلة جامعة النجاح للأبحاث ، مجلد ب . ץ-أبو غزالة، سميرة علي (2007) : فاعلية الإرشاد بالمعنى في تخفيف أزمة الهوية وتحسين المعنى الإيجابي للحياة لدى طلاب الجامعة، المؤتمر السنوي الرابع عشر لمركز الإششاد

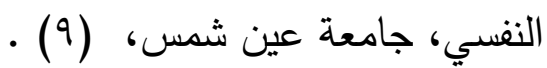

ع - الأبيض ، محمد حسن ( • • · ) : مقياس معنى الحياة لدى الثباب ، مجلة كلية التربية ،

جامعة عين شمس ، العدد ( ؟r ) .

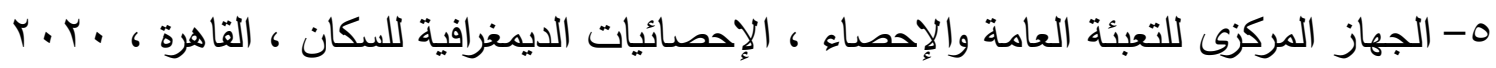


צ- الدسوقي , سميرة إبراهيم ( 9 ( ب ) ) الخدمة الاجتماعية في مجال رعاية المسنين ، القاهرة ، مطبعة هاني للنشر V- الرشيدى ، هارون توفيق ( 1999 ) : معنى الحياة والتحكم الذاتى لدى عينة من طلاب الجامعة ، مجلة البحوث النفسية والتربوية ، كلية التربية ، جامعة المنوفية ، ( r) ، (1 (1 ) .

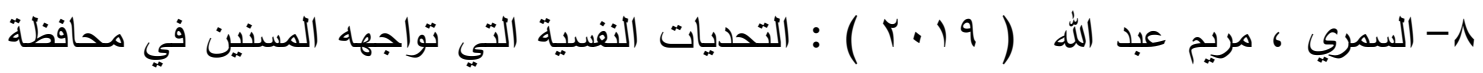
مسقط دراسة تحليليه ، عمان ، جامعة السلطان قابوس الخوض ،كلية آداب والعلوم الاجتماعية

9- الشعرواى ، صالح فؤاد محمد (ع ا • ) ) : فعالية العلاج بالمعني في تحسن جودة الحياة لدي عينة من الشباب الجامعي ، بحث منشور في مجلة دراسات عربية في التربية وعلم النفس ،

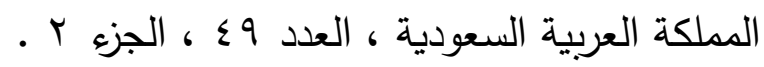

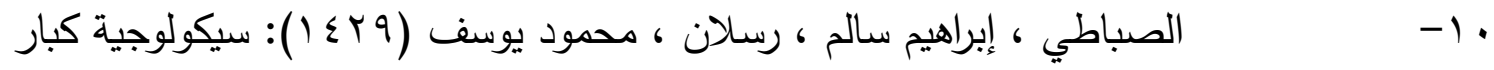
السن ، جامعة الملك فيصل ، الهفوف .

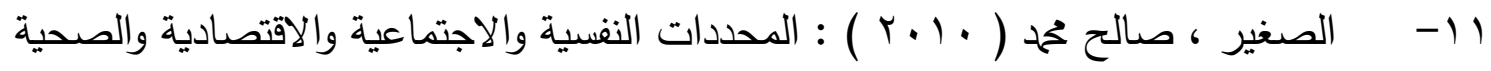
المؤثرة في مستوي الرضا عن الحياة لدي المتقاعدين ، السعودية ، جامعة الملك سعود ، قسم

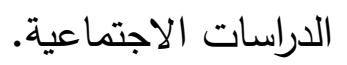

rا- العايش ، زينب محم زين ( 1997 ) ) : مدي فعالية العلاج بالمعني كأسلوب إشادي في تخفيض بعض الإضطرابات السلوكية في مرحلة المراهقة ، بحث منشور في مجلة الإرشاد النفسي ، كلية التربية ، جامعة عين شمس ، العدد ه ، الجزء ؛ .

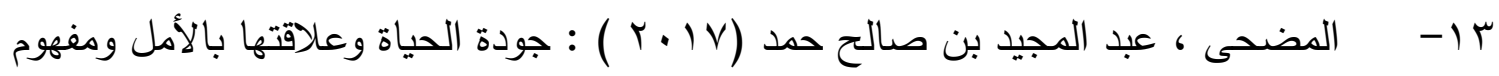
الذات لدي الأحداث الجانحين وغير الجانحين بمدينة الرياض ، رسالة ماجستير ، كلية العلوم الإجتماعية ، جامعة الإمام محمد بن سعود الإسلامية . ع ا- بلان ، كمال يوسف (10 ب ) ) نظريات الإرشاد والعلاج النفسي ، طا ، دار الإعصار العلمي للنشر ، دمشق • الع 


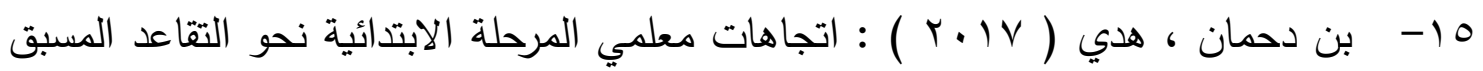
دراسة ميدانيه ببعض مدارس الابتدائية بدائرة بن سرور ، جامعة محمد بوضباف- المسيلة ، كلية العلوم الإنسانية والاجتماعية، قسم علم نفس.

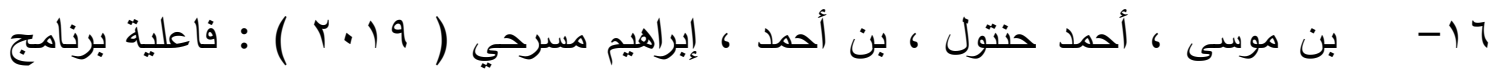
إرشادي قائم علي العلاج بالمعني في تحسين مستوي الطموح لدي طلاب المرحلة الثانوية بمنطقة جازان ، بحث منشور في مجلة كلية التربية ، جامعة الزقازيق ، العدد بـ ا ، الجزء • الثاني

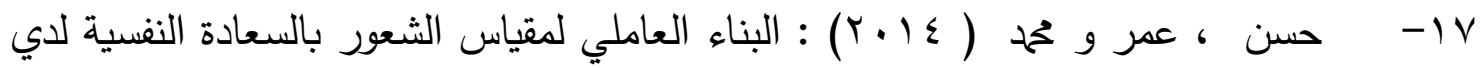
كبار السن ، جامعة المنصورة ، مجلة كلية التربية الرياضية ، العدد ؟ ـ

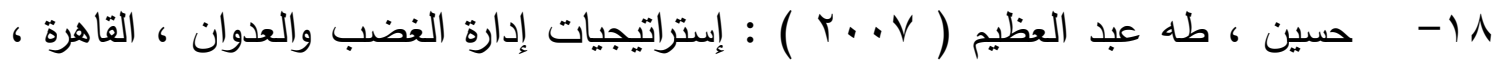

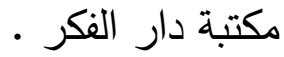

9 19- خليفة ، عبداللطيف محم (1997) : دراسات في سيكولوجية المسنين ، القاهرة ، دار • غريب للطباعة والنشر

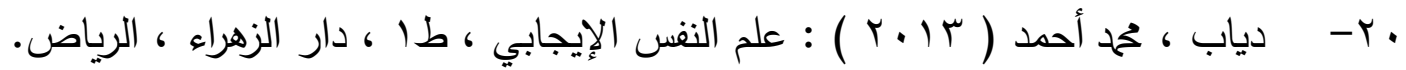

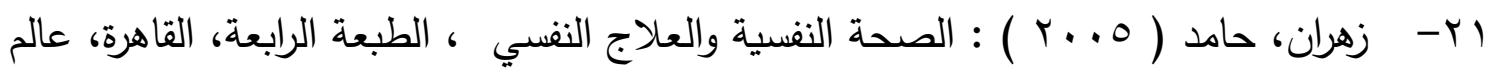
الكتب.

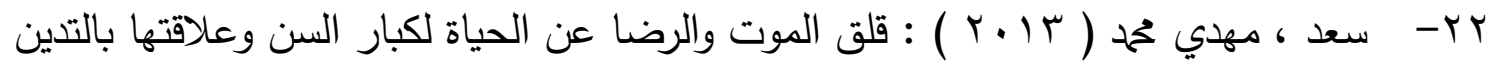
وكيفية قضاء بعض الوقت وبعض التغيرات الديموغرافيه، الأردن ، رسالة دكتوراه ، كلية

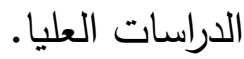

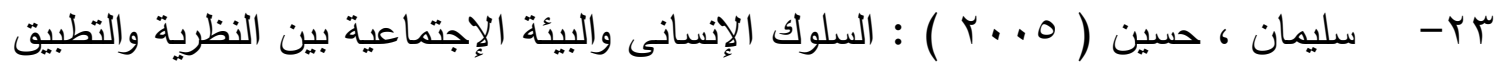
، بيروت ، المؤسسة الجامعية الحديثة للنشر والتوزيع • http://omar.socialindex.net/intro11.htm ،

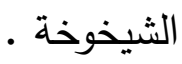




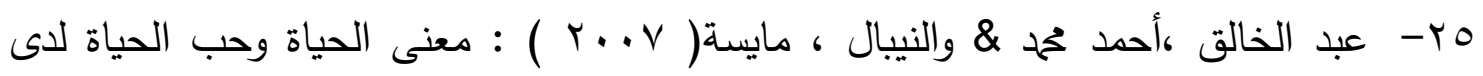
مجموعة مختلفة من مريضات السرطان -دراسة مقارنة ،المؤتمر الإقليمى الأول لعلم النفس .

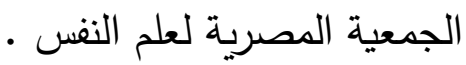

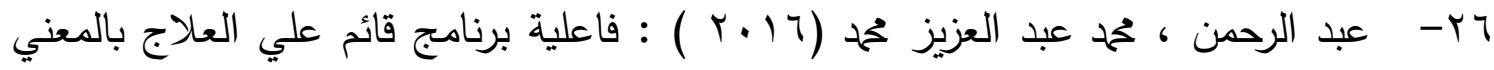
لتحسين الههف من الحياة لاي مجموعة من المراهقين الصم ، بحث منشور في مجلة كلية

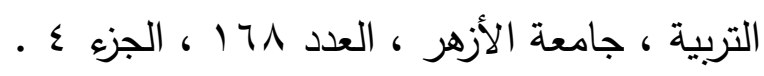

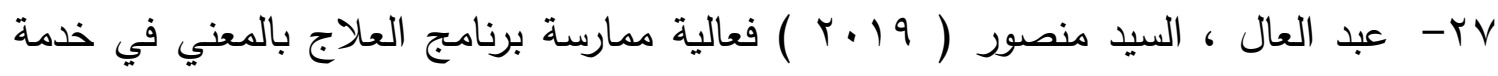
الفرد لتحسين التوجه نحو الحياة للأحداث الضالين ، بحث منشور فى مجلة دراسات فى الخدمة الإجتماعية والعلوم الإنسانية . كلية الخدمة الإجتماعية جامعة حلوان ، العدد ^ــ .

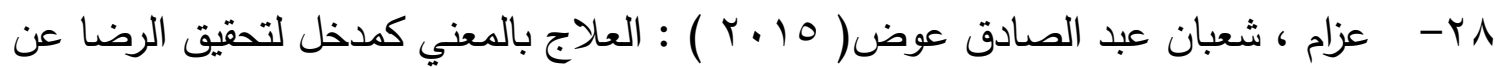
الحياة للمعاقين حركيا ، بحث منشور في مجلة دراسات في الخدمة الإجتماعية والعلوم الإنسانية ، كلية الخدمة الإجتماعية ، جامعة حلوان ، العدد مب ، الجزء ـ. qץ- عيسوي ، عبدالرحمن، سيكولوجية الثيخوخة ، دار المعرفة الجامعية ، جامعة الاسكندرية • ץ- فدعوس ، نايف علوان \& الرشيدى ، حمود أحمد لزام (10 ب) : فاعلية الإششاد والعلاج بالمعني في التخفيف من ضغوط ومشكلات الحياة النفية لدي طلبة الجامعة ، بحث منشور في مجلة الطفولة والتربية ، كلية رياض الأطفال ، جامعة الأسكندرية ، العدد ع ، ، المجلد V . اب- فوزى ، ايمان ( 1991 ) ) : إرادة المعني أسس وتطبيقات العلاج بالمعني ( تأليف فيكتور إيميل فرانكل ، دار زهراء الشرق ، القاهرة .

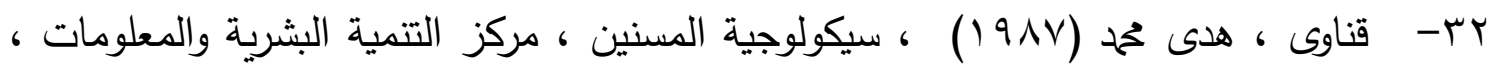

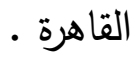
r ب- كتلو كامل، عبدالله تيسير (1) (1) : نوعية الحياة وعلاقتها بالصحة النفسية، مجلة علم

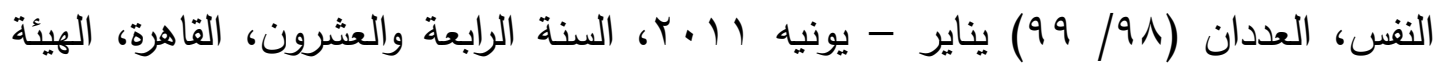

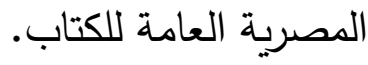




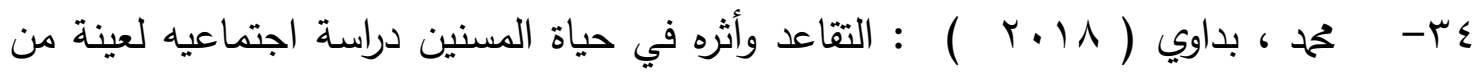
الدتقاعدين ، السعودية ، جامعة أبو بكر بلقايد ، رسالة دكتوراه ، كلية العلوم الإنسانية والعلوم

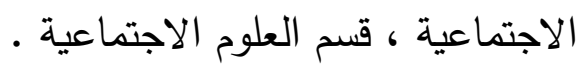

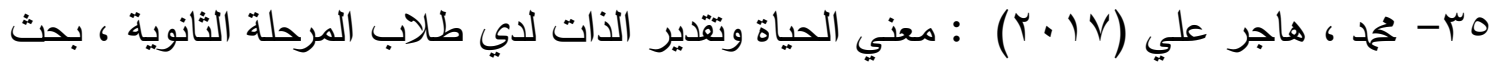

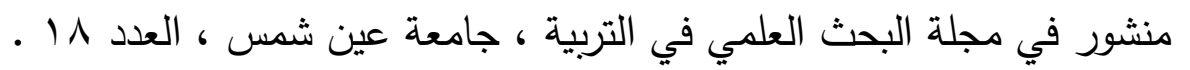

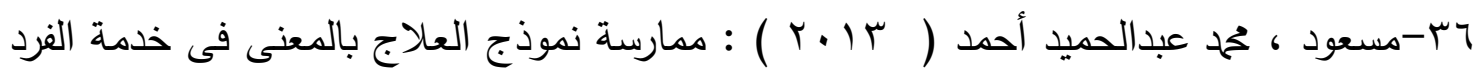

للتخفيف من الآثار الناتجةعن الطلاق المبكر للثابات حديثى الزواج فى المناطق العشوائية ،

بحث منشور ، المؤتمر العلمي الدولي السادس والعشرون للخدمة الاجتماعية ـ كلية الخدمة

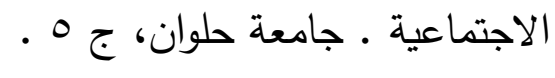

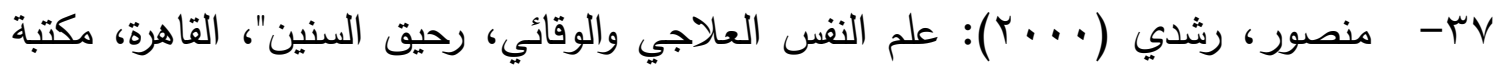

$$
\begin{aligned}
& \text { الأنجلو الصصرية. } \\
& \text { المراجع الأجنبية: }
\end{aligned}
$$

38- Frankl, V. (1990): The Will of Meaning. New York,: Penguin Books.

39- Kimble, $\mathbf{m}$ \&Ellor, $\mathbf{t}$ (2000). Logotheraphy an overview. Journal of religious gerontology, vol (1), n 3-9.

40- Hodger, P. (2008): life Purpose, Heath- Related Quality of Life, and Hospital Readmissions among older adults with heart failure, Unpublished Doctoral Dissertation University of Texas, Texas.

41- Elosua, Paula. (2011). Subjective Values of Quality of Life Dimensions in Elderly People. A SEM Preference Model Approach. Springer Science Business Media. Soc Indic Res.

42- Stanil A. Gabriel. (2015). THE QUALITY OF LIFE OF THE ELDERLY IN ROMANIA. Journal of Community Positive Practices, XV (2) 2015, P 18- 27.

43- Singh, P; Govil, D.; Kumar, V.; Kuma, J. (2017). Cognitive Impairment and Quality of Life among Elderly in India. Springer Science Business Media Dordrecht and The International Society for Quality-of-Life Studies (ISQOLS). Applied Research Quality Life (2017) 12:963-979. 
44- Smith, E. A. (2000). Quality of Life: a review. Education and Ageing, 15(3), 419-435.

45- Leung, Mei- Yung, Yu, Jingyu \&Chong, Ming. (2017). Impact of facilities management on the quality of life for the elderly in care and attention homes - Cross-validation by quantitative and qualitative studies. Indoor and Built Environment 2017, Vol. 26(8) 1070-1090.

46- Longest J. (2008). Quality of life impact in mental health needs, New York, Institute of Education Sciences.

47- Lukas, Elisabeth; Hirsch, Bianca Zwang (2002): Logo therapy, in Kaslow, Florence W. (Ed), Comprehensive handbook of psychotherapy: Interpersonal /humanistic /existential, Vol. 3. , NJ, US: John Wiley \& Sons Inc,. p. 333

48- Maria Marshall; Edward Marshall (2012): Logo therapy Revisited: Review of the Tenets of Viktor E. Frankl's Logo therapy. Ottawa Institute of Logo therapy. ISBN 978-1-4781-9377-7.

49- Bill O'Hanlon, (2013): Possibility Therapy, from iatrogenic injury to iatrogenic healing N.Y.W.W.norton, p 143.

50- Frankl, $\mathbf{V}:(2011)$ : the unheard cry for meaning psychotherapy and Humanism, New York, p, 345.

51- Document Education Department of Education Republic of South Africa (2003): National Curriculum Statement Grades 10-12 (General) LIFE ORIENTATION.

52- Anderson, S (2003): Quality of life Theory. The Igol Theory, the Quality of life Research center, Copenhagen, Denmark, ventegodt@Livsk valitet.org.

53- Frankle, Victor E. man (2020) :, search for meaning, an introduction to logo therapy, Boston : Beacon Press. 


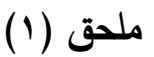

الجلسات المقترحة لبرنامج العلاج بالمغنى لتحسين معنى الحياه لاى المسنين المتقاعدين :

$$
\begin{aligned}
& \text { يشتمل البرنامج العلاجى المقترح على (0) (10) جلسة علاجية بمعدل جلستين اسبو عيا مدة كل جلسة ( 9) دقيقة ويوضح الجدول }
\end{aligned}
$$

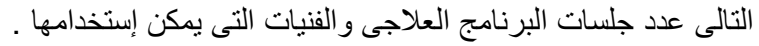

جدول يوضح جلسات برنامج العلاج بالمعنى فى تحسين معنى الحياة للمسنين المتقاعدين

\begin{tabular}{|c|c|c|c|c|}
\hline المستخدمة & إجر اءات الجلسة & أهداف الجلسة & الجلسة & الجلسة \\
\hline والمحاضثة & 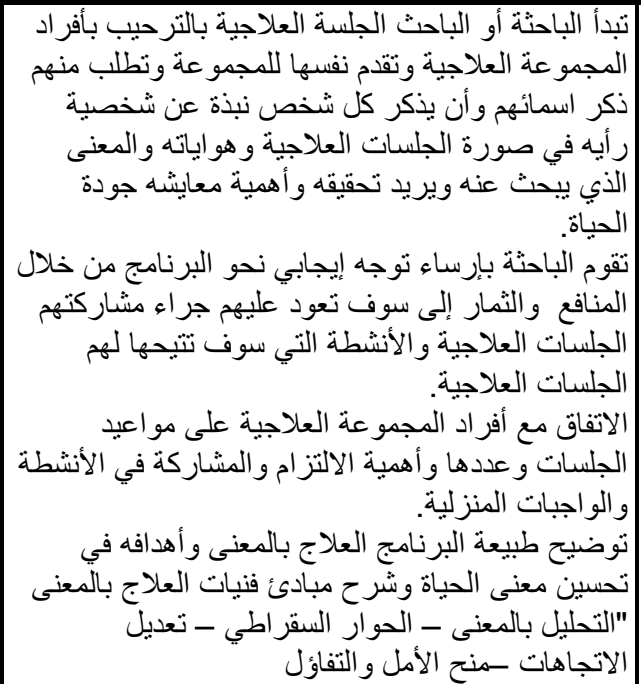 & 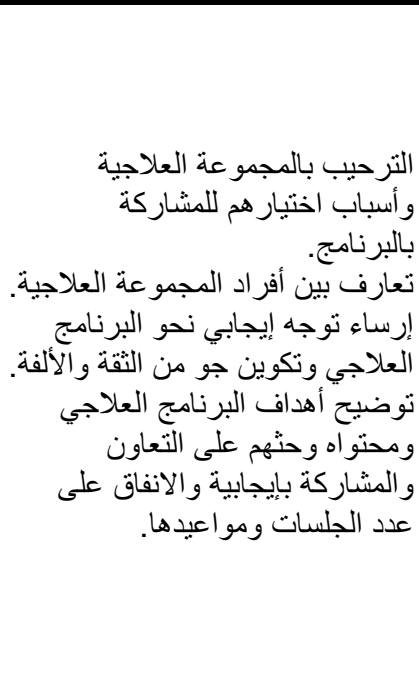 & العلاقة & $r-1$ \\
\hline المناقشة الحوار & 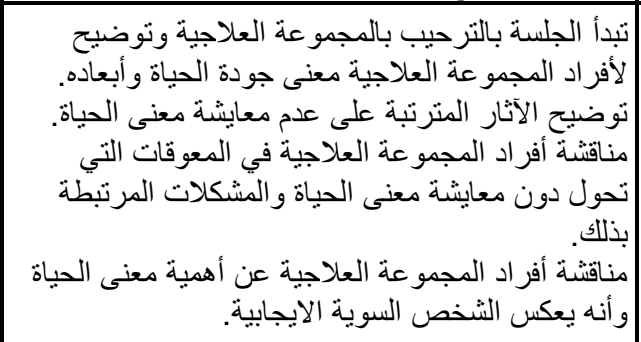 & 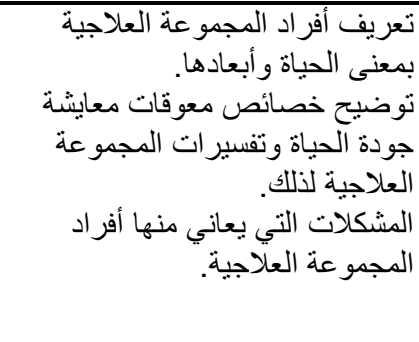 & جودة الحياة & $\varepsilon-\Gamma$ \\
\hline المناقشة تحليل & 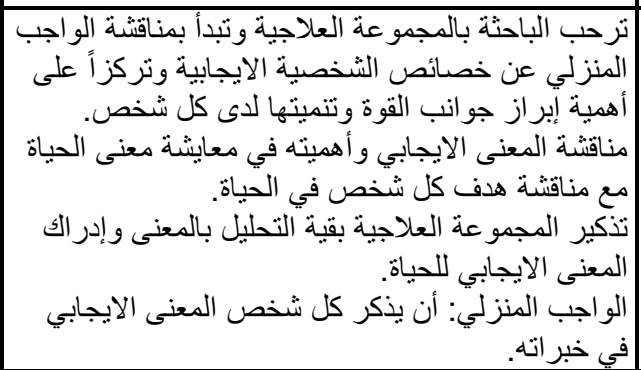 & فو توضيح معايشة جودية المعنى الحياة. الإيجابي للحياة & بالمعلى & 7.0 \\
\hline 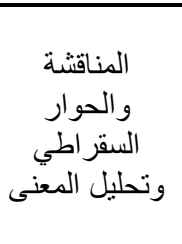 & 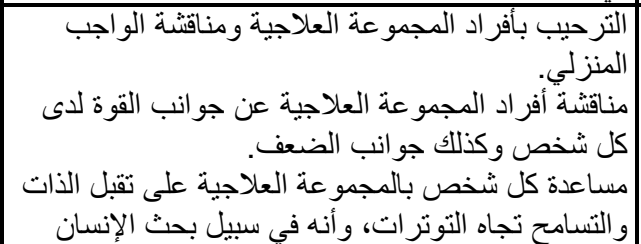 & 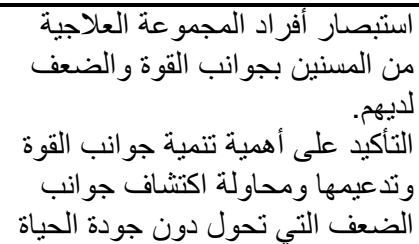 & الذتنشات & $\Lambda_{-} \mathrm{V}$ \\
\hline
\end{tabular}




\begin{tabular}{|c|c|c|c|c|}
\hline & 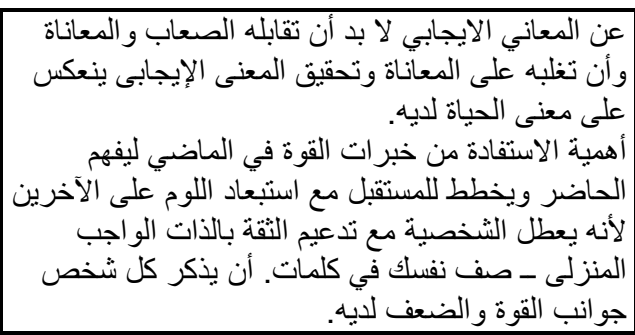 & 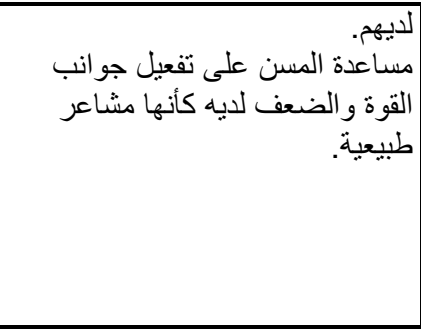 & & \\
\hline الاتجاقشة تعديل & 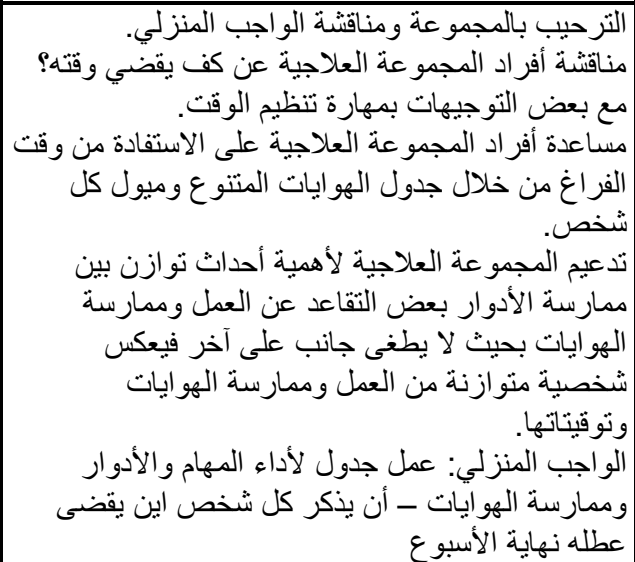 & 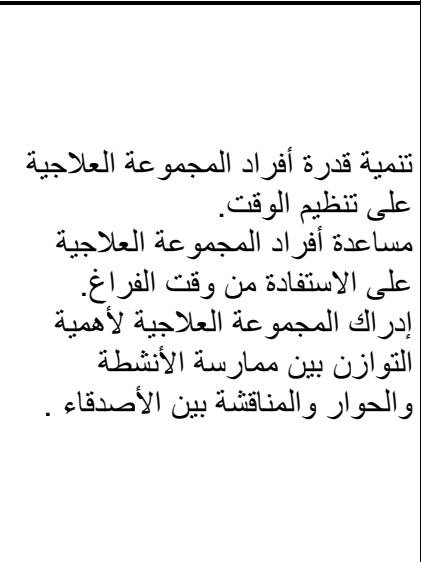 & الوقارة & 9 \\
\hline 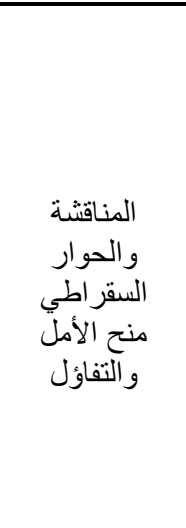 & 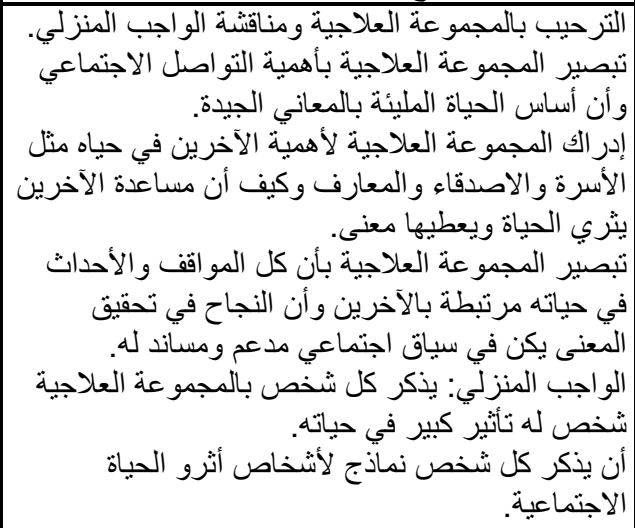 & 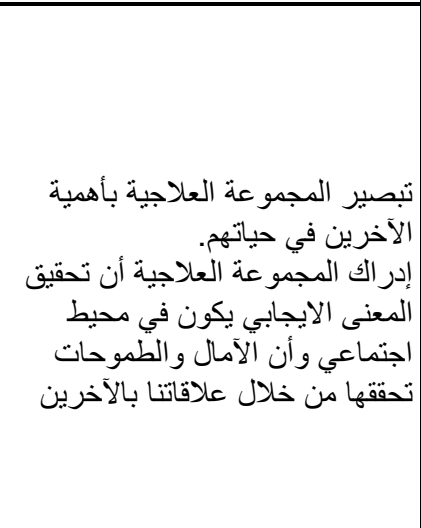 & الاجنماعي التو اصل & 1. \\
\hline السقر اطي تحليل الحو ار & 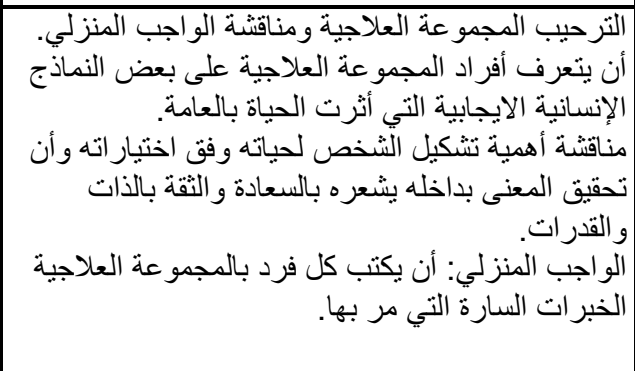 & 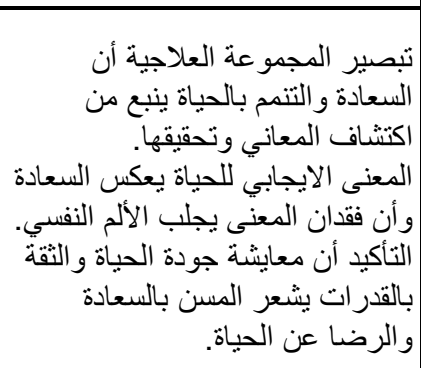 & السعادة & 11 \\
\hline السقر اطوار الإتجاهات & 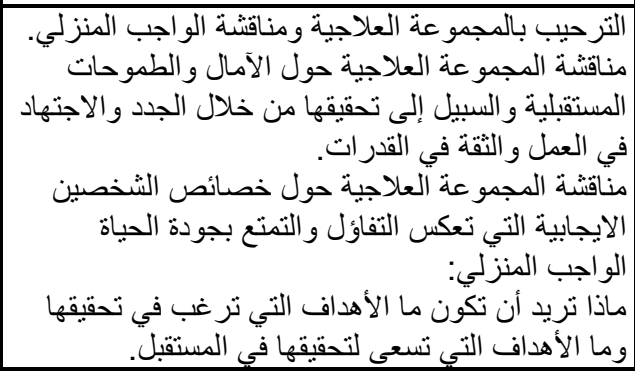 & 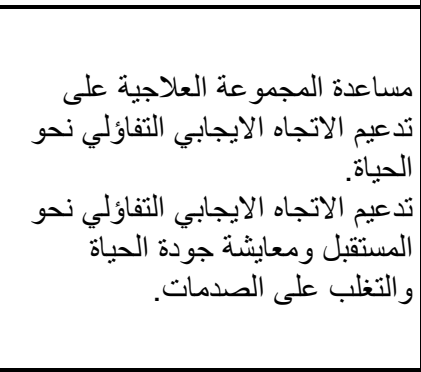 & التفاؤل & Ir \\
\hline
\end{tabular}




\begin{tabular}{|c|c|c|c|c|}
\hline و المناقشة الحة & 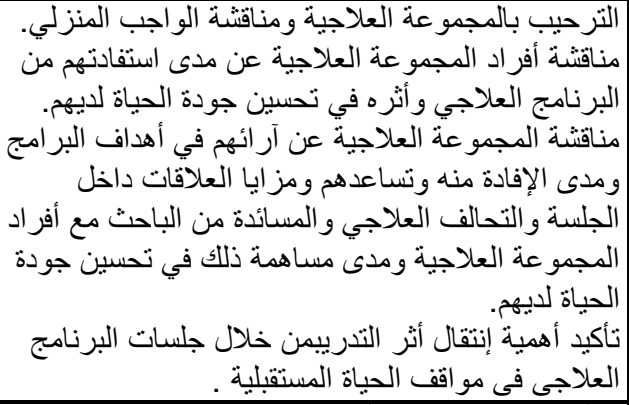 & 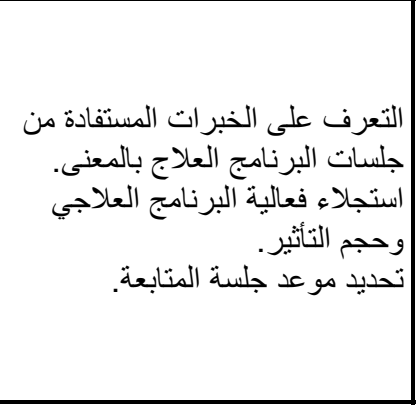 & البرناميج & $1 \leq-1 T$ \\
\hline و المناقشتة & 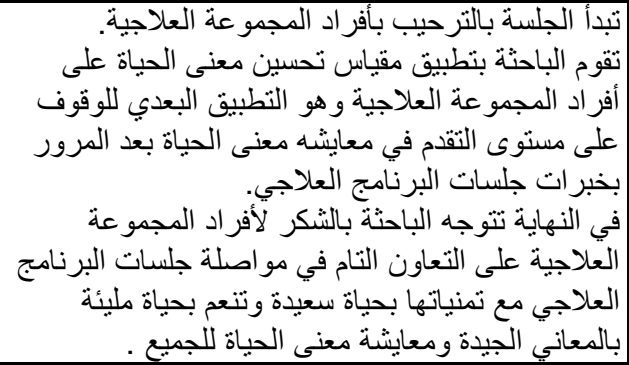 & 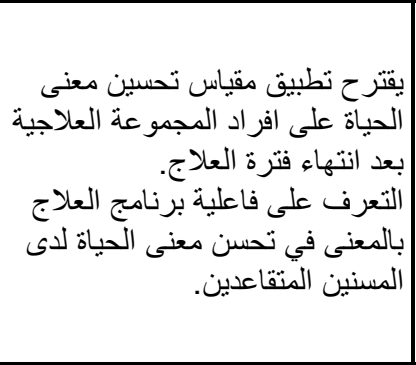 & التبرنيم أثر & 10 \\
\hline
\end{tabular}

